\title{
Gene therapy-mediated enhancement of protective protein expression for the treatment of Alzheimer's disease
}

Lauren V. Owens ${ }^{\mathrm{a}}$, Alexandre Benedetto ${ }^{\mathrm{a}}$, Neil Dawson ${ }^{\mathrm{a}}$, Christopher J. Gaffney ${ }^{\mathrm{b}}$, Edward T. Parkin $^{\mathrm{a}^{*}}$

${ }^{a}$ Division of Biomedical and Life Sciences, Faculty of Health and Medicine, Lancaster University, Lancaster, LA1 4YG, UK.

bLancaster Medical School, Faculty of Health and Medicine, Lancaster University, Lancaster, LA1 4YG, UK.

*Correspondence to: Edward T. Parkin, Division of Biomedical and Life Sciences, Faculty of Health and Medicine, Lancaster University, Lancaster, LA1 4YG, UK. Telephone: +44 (0)1524 592246. E-mail: e.parkin@lancaster.ac.uk.

\begin{abstract}
Abbreviations
$A A V$, adeno-associated virus; $A D$, Alzheimer's disease; ADAM, a disintegrin and metalloprotease; AICD, amyloid precursor protein intracellular domain; ApoE, apolipoprotein $E ; A P P$, amyloid precursor protein; ARE, antioxidant response element; $A \beta$, amyloid beta; BACE1, $\beta$-site amyloid precursor protein cleaving enzyme 1; BBB, blood-brain barrier; BDNF, brain-derived neurotrophic factor; CBP, cyclic adenosine monophosphate-response element binding protein binding protein; CREB, cyclic adenosine monophosphate-response element binding protein; CTF, C-terminal fragment; ECE, endothelin converting enzyme; GLP-1, glucagon-like peptide 1; GPI, glycosylphosphatidylinositol; GSK-3 $\beta$, glycogen synthase kinase $3 \beta$; HSP, heat-shock protein; HSV, herpes simplex virus; $I_{1} P P 2 A$, protein phosphatase $2 \mathrm{~A}$ inhibitor 1; I 2 PP2A, protein phosphatase $2 \mathrm{~A}$ inhibitor 2; IL, interleukin; MAPK; mitogenactivated protein kinase; NEP, neprilysin; NFTs, neurofibrillary tangles; NGF, nerve growth factor; NMDA, N-methyl-D-aspartate; NO, nitric oxide; Nrf2, nuclear factor E2-related factor 2; NSE, neuron-specific enolase; PHFs, paired helical fragments; PP2A, protein phosphatase $2 \mathrm{~A}$; PPAR $\gamma$, peroxisome proliferator-activated receptor gamma; PrP, prion protein; PS, presenilin; RCAN1, Regulator of Calcineurin 1; ROS, reactive oxygen species; SAPP $\alpha$, soluble amyloid precursor protein alpha; SAPP $\beta$, soluble amyloid precursor protein beta; $\mathrm{SeV}$, sendai virus; Tet, tetracycline; TFEB, transcription factor EB; TIIDM, type II diabetes mellitus; TNFa, tumour necrosis factor alpha; TREM2, triggering receptor expressed on myeloid cells 2 .
\end{abstract}




\begin{abstract}
Alzheimer's disease (AD) is the leading form of dementia but lacks curative treatments. Current understanding of $A D$ aetiology attributes the development of the disease to the misfolding of two proteins; amyloid- $\beta(A \beta)$ and hyperphosphorylated tau, with their pathological accumulation leading to concomitant oxidative stress, neuroinflammation, and neuronal death. These processes are regulated at multiple levels to maintain homeostasis and avert disease. However, many of the relevant regulatory proteins appear to be downregulated in the AD-afflicted brain. Enhancement/restoration of these 'protective' proteins, therefore, represents an attractive therapeutic avenue. Gene therapy is a desirable means of achieving this because it is not associated with the side-effects linked to systemic protein administration, and sustained protein expression virtually eliminates compliance issues. The current article represents a focused and succinct review of the better established 'protective' protein targets for gene therapy enhancement/restoration rather than being designed as an exhaustive review incorporating less validated protein subjects. In addition, we will discuss how the risks associated with uncontrolled or irreversible gene expression might be mitigated through combining neuronal-specific promoters, inducible expression systems and localised injections. Whilst many of the gene therapy targets reviewed herein are yet to enter clinical trials, preclinical testing has thus far demonstrated encouraging potential for the gene therapy-based treatment of AD.
\end{abstract}

Keywords: Alzheimer's disease; gene therapy; protective proteins; amyloid beta; tau 


\section{Introduction}

Alzheimer's disease (AD) is the predominant neurodegenerative disorder globally, with worldwide cases predicted to reach 75 million by 2030 (Prince et al. 2015). AD presents clinically with a progressive decline in memory and cognitive function, ultimately leading to death following complications including malnutrition or pneumonia. The pathological hallmarks of $A D$ are the deposition of extracellular amyloid plaques (primarily in the cerebral neocortex) consisting of amyloid- $\beta$ (A $\beta$ ) peptide (Thal et al. 2002), and neurofibrillary tangles (NFTs; originating in the entorhinal cortex) formed by abnormally phosphorylated aggregations of the microtubule-associated protein tau (Braak \& Braak 1991). Plaques and tangles can develop in the brain three decades before clinical symptoms manifest (Perl 2010).

\subsection{Abnormal protein aggregates are central to the aetiology of $A D$}

Two well-accepted hypotheses tentatively explain the aetiology of AD. The 'amyloid hypothesis' (Hardy \& Allsop 1991; Selkoe 1991) attributes disease development to the abnormal accumulation of 39-43 amino acid A $\beta$-peptides (Nunan \& Small 2000). A $\beta$-peptides are formed by cleavage of the amyloid precursor protein (APP), an integral membrane protein concentrated at neuronal synapses (Priller et al. 2006). APP can be proteolytically cleaved via the amyloidogenic or the non-amyloidogenic pathways (Figure 1). In the latter, an $\alpha$-secretase from the $\underline{A}$ Disintegrin And Metalloprotease (ADAM) family initiates juxta-membrane cleavage at the Lys16-Leu17 bond within the AB-peptide region (Anderson et al. 1991). This generates soluble APP $\alpha$ (SAPP $\alpha$ ) and a membrane-bound C-terminal fragment (CTF $\alpha$ ). Further cleavage of CTF $\alpha$ by the $\gamma$-secretase complex produces the APP intracellular domain (AICD) and the short P3 peptide (Chow et al. 2010).

In the amyloidogenic pathway, APP is cleaved $\mathrm{N}$-terminally to Asp1 of the $A \beta$ region by $\beta$-secretase ( $\beta$-site APP cleaving enzyme 1, BACE1), yielding soluble APP $\beta$ (sAPP $\beta$ ) and CTF $\beta$ (Vassar et al. 1999). Subsequent intramembrane cleavage of CTF $\beta$ by the $\psi$-secretase complex produces $A I C D$ and $A \beta$-peptides, the latter of which exist in two predominant forms; an abundant 40 amino acid form $\left(A \beta_{(1-40)}\right)$ and a more hydrophobic 42 amino acid form $\left(A \beta_{(1-42)}\right)$ prone to aggregation (Mori et al. 1992; Jarrett et al. 1993). Aggregated $A \beta$ initially forms oligomers before progressing through a protofibril intermediate to form mature fibrils (Verma et al. 2015). Mature fibrils were initially thought to cause the neurotoxicity observed in AD, but $A \beta$ oligomers were subsequently identified as the primary neurotoxic species (He et al. 2012; Nimmrich et al. 2008).

The amyloid hypothesis is supported by the identification of mutations in APP and PRESENILIN (PS1 and PS2) genes that pre-dispose to $A D$, and are associated with increased levels of $A \beta$-peptides or a higher ratio of $A \beta_{(1-42)}$ to $A \beta_{(1-40)}$ (Goate et al. 1991; Lanoiselée et al. 2017). In healthy individuals, $A \beta$-peptides are rapidly degraded by various proteases that collectively target monomeric, oligomeric and fibrillar forms (Saido \& Leissring 2012). The ability to degrade $A \beta$-peptide decreases with age and following oxidative stress (Caccamo et al. 2005; Shinall et al. 2005; Wang et al. 2003) and is reduced in AD subjects (Mawuenyega et al. 2010). Additionally, clearance of $A \beta$-peptides from the brain into the circulation by low density lipoprotein receptor-related protein 1 may be defective in $A D$, although this remains 
controversial [Reviewed in Shinohara et al. (2017)]. Nevertheless, failure to remove ABpeptides through degradation or clearance processes leads to their accumulation and aggregation in the brain.

The second hypothesis of $A D$ pathogenesis proposes that the hyperphosphorylation of tau is the causative event. Physiologically, tau phosphorylation is responsible for the polymerisation and stabilisation of microtubules, key components of the cellular cytoskeleton (Weingarten et al. 1975). In the human brain, alternate splicing of the MAPT gene produces six different tau isoforms (Goedert et al. 1989). In $A D$ all isoforms of tau are hyperphosphorylated, resulting in dissociation from microtubules and aggregation into paired helical filaments (PHFs) that comprise the NFTs characteristic of AD (Grundke-lqbal et al. 1986).

NFT hyperphosphorylated tau cannot bind tubulin or promote microtubule formation (Alonso et al. 2006). In its non-fibrillised hyperphosphorylated form, tau also prevents binding of lesser phosphorylated tau to tubulin. This destabilises existing microtubules and promotes the formation of degradation-resistant insoluble PHFs (Alonso et al. 1994; Yamada et al. 2015). This accumulation of insoluble tau impairs axonal transport (Cabrales Fontela et al. 2017), compromises mitochondrial integrity (DuBoff et al. 2012) and impairs synaptic function (Zhou et al. 2017), eventually leading to neuronal loss.

The amyloid and tau hypotheses are not mutually exclusive. For example, A $\beta$-peptides can induce tau phosphorylation through mitogen-activated protein kinase (MAPK) p38 or glycogen synthase kinase $3 \beta$ (GSK-3 $\beta$ ) signalling (Terwel et al. 2008; Zheng et al. 2002; Zhu et al. 2000). Indeed, A $\beta$-induced oxidative stress increases Regulator of Calcineurin 1 (RCAN1) expression, which inhibits calcineurin and promotes GSK-3 $\beta$ expression (Lloret et al. 2011). This increases GSK-3 $\beta$ content and promotes $A \beta$-peptide neurotoxicity (Koh et al. 2008).

Calcineurin inhibition and GSK-3 $\beta$ upregulation can both increase hyperphosphorylated tau levels, by inhibiting tau dephosphorylation and promoting tau hyperphosphorylation, respectively (Wei et al. 2002). Similarly, A $\beta$-induced oxidative stress increases MAPK p38 activation in APP/PS1 transgenic mice, supporting a multi-mechanistic action of $A \beta$-peptide in tau hyperphosphorylation (Giraldo et al. 2014).

\subsection{AD-associated protein aggregates promote oxidative stress and neuroinflammation}

Oxidative stress has been implicated in the pathogenesis of $A D$, possibly through $\mathrm{Cu}^{2+}$ binding to $A \beta$-peptides (Jiang et al. 2007) generating neurotoxic reactive oxygen species (ROS) such as HO (Guilloreau et al. 2007). ROS oxidise lipids, proteins, and DNA (Dorfman \& Adams 1973), leading to cell death through membrane lipid peroxidation, the impairment of cellular metabolism, or mitochondrial DNA damage (Markesbery 1997; Tramutola et al. 2017).

Neuroinflammation is also critically involved in AD (Rogers et al. 1988). A $\beta$ oligomers and fibrils bind to immune cell receptors such as CD14, CD36, scavenger receptor $A$, and tolllike receptors 4 and 6 (Hickman et al. 2008; Liu et al. 2005b; Stewart et al. 2010), inducing microglial cells to release pro-inflammatory cytokines and migrate into plaques to phagocytose $A \beta$-peptides in an attempt to clear them (Stalder et al. 1999). Astrocytes also 
release cytokines and nitric oxide (NO), while accumulating around $A \beta$-peptide brain deposits (Beach \& McGeer 1988). As the disease progresses, chronic activation of brain immune cells results in the sustained production of pro-inflammatory molecules and reduced $A \beta$ clearance (Hickman et al. 2008). More recently, tau has also been implicated in neuroinflammation, following its colocalization with astrocytes and microglia (Nilson et al. 2017). In glial cell cultures, truncated tau increases NO levels, and activates the MAPK pathway, leading to tau hyperphosphorylation (Zhu et al. 2000), and increases proinflammatory cytokines including

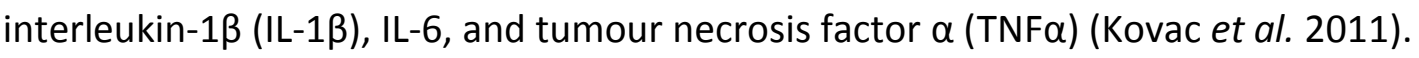

Hence, $A \beta$ deposition and tau hyperphosphorylation contribute to oxidative stress and neuroinflammation, which further exacerbate the disease.

\subsection{Current drug treatments for $A D$ are limited to symptomatic relief}

Four drugs are currently licensed for $A D$ treatment. The acetylcholinesterase inhibitors (donepezil, rivastigmine, and galantamine) enhance cholinergic neurotransmission and compensate for cholinergic neurodegeneration (Mehta et al. 2012), while the noncompetitive N-methyl-D-aspartate (NMDA) receptor antagonist memantine limits excitotoxicity-induced neurodegeneration (Schmitt 2005; van Marum 2009). Neither treatment is curative, only temporarily managing AD symptoms (Areosa et al. 2005; Farlow 2002). Treatments that target the causative factors of $A D$ are, therefore, required.

Whilst many small molecule drugs and protein/peptide-based treatments have reached clinical trials, few afford great benefit in $A D$ due to lack of efficacy, side-effects and compliance issues (Mehta et al. 2017). AD is a long-term disease which makes the inducible upregulation of therapeutic proteins (e.g. by gene therapy) an attractive proposition (Nikol \& Huehns 2001). Gene therapy could involve: (1) replacing a known deleterious allele with a functional copy, or (2) boosting the expression of beneficial proteins (Somia \& Verma 2000). As $A D$ is largely idiopathic, the former applies to a minority with familial inheritance, while the latter potentially applies to a broader range of patients and is thus the focus of the current gene therapy development, reviewed herein.

\section{Enhancing protective protein expression by gene therapy for AD}

\subsection{Gene therapies that modulate pathogenic protein aggregation as potential treatments for AD}

\subsubsection{Reducing the generation of $A \beta$-peptides}

Although a myriad of drugs have been developed that, mechanistically, impair $\beta$ - or $\gamma$ secretase function (reviewed in Zhao et al. 2020), with a view to reducing A $\beta$-peptide generation few, if any, have resulted in an appreciable reduction in the rate of cognitive decline in patients (reviewed in Zhao et al. 2020; Kumar et al. 2018; Selkoe 2019). Such failures are exemplified no more effectively than by the recent late stage clinical trial failures of BACE1 inhibitors such as MK8931, AZD-3293, JNJ-54861911, E2609 and CNP520 which have not only shown little clinically relevant improvement in cognitive performance but, in some cases, have even worsened cognitive function (Moussa-Pacha et al. 2020; Wessels et al. 2020). There 
is, therefore, a clear requirement for alternative strategies geared towards reducing $A \beta-$ peptide generation.

Surprisingly few therapeutic opportunities for enhancing protective protein expression to impair the generation of $A \beta$-peptides have been identified. The regulation of APP proteolysis has been closely linked to cholesterol metabolism and the lateral segregation of the protein and its secretases between lipid raft and non-raft regions of the cell membrane (reviewed in Arbor et al. 2016). The clearance of cholesterol from the brain is dependent on the conversion of the lipid into 24S-hydroxycholesterol (24S-HC) which, unlike cholesterol, can freely cross the blood-brain-barrier. 24S-HC, generated from cholesterol by the action of cholesterol 24-hydroxylase (endoded by the CYP46A1 gene), has been shown to enhance $\alpha$ secretase activity and increase the $\alpha$ - to $\beta$-secretase activity ratio (Famer et al. 2007). Hudry et al. (2010) subsequently showed that adeno-associated virus gene therapy with CYP46A1 reduced amyloid pathology both before and after the onset of plaque deposition in APP23 transgenic mice. The authors further suggested that, mechanistically, the phenomenon might involve a reduced recruitment of APP and presenilin 1 to lipid rafts. Similarly, the overexpression, in APP/PS1 transgenic mice, of the transcription factor Forkhead box 01 (FoxO1), involved in the regulation of cell growth, differentiation and metabolism, has been shown to significantly decrease A $\beta$-peptide production through an attenuation of amyloidogenic APP processing by the $\beta$ - and $\gamma$-secretases (Zhang et al. 2020).

Changes in endosomal morphology and function are early events in the AD-afflicted brain (reviewed in Nixon et al. 2000) and the lysosomal compartment has been linked to disease progression through reduced autophagic clearance and the accumulation of lysosomal cathepsins in amyloid plaques (Nixon et al. 2006). Therefore, it is possible that enhancing the expression of proteins that promote lysosomal function might represent a viable therapy for $A D$ although such global cellular changes may have unintended and undesirable consequences. However, some precedent does exist in this respect. Annunziata et al. (2013) showed that mice deficient in the lysosomal sialidase neuramindase 1 (NEU1) spontaneously developed amyloid plaques. The authors proposed that this resulted from the lysosomal accumulation of an 'oversialylated' form of APP (resulting in enhanced amyloidogenic processing of the protein) together with enhanced extracellular release of $A \beta$ peptides due to excessive lysosomal exocytosis. Most importantly, in the context of the current review, adenoviral-mediated restoration of NEU1 expression in 5XFAD mice through hippocampal stereotactic injection resulted in a dramatic decrease in plaque pathology leading the authors to conclude that enhancing NEU1 expression might represent a novel therapy for the treatment of AD.

However, as far as enhancing protective protein expression with a view to reducing $A \beta$-peptide generation is concerned, by far the most research in this respect has been conducted on the non-amyloidogenic secretase ADAM family of enzymes. Several ADAM family members have been implicated as potential $\alpha$-secretases, including ADAMs $8,9,10$, 17, 19 and 33 (reviewed in Gough et al. 2011), however, only in the case of ADAM10 has the over-expression of the protein in vivo been shown to result in an appreciable lowering of $A \beta$ peptide plaque burden in an animal model (Postina et al. 2004). Interestingly, ADAM9 was 
first shown to enhance SAPP $\alpha$ production in cell cultures by Koike et al. (1999) but was subsequently shown to require the presence of ADAM10 for its ability to cleave both APP and PrP (Cissé et al. 2005). Our group was the first to show that ADAM9 was capable of proteolytically shedding ADAM10 from the cell surface (Parkin \& Harris 2009) which presented somewhat of a paradox given that the former enzyme had previously been shown to enhance SAPP $\alpha$ generation (Koike et al. 1999). This was further compounded by the subsequent confirmation that inhibiting ADAM9 using a recombinant form of its prodomain increased membrane-associated levels of ADAM10 resulting in enhanced $\alpha$-secretase processing of APP (Moss et al. 2011). Whilst this latter observation might not explain the apparent paradox, it does open up the possibility of enhancing the expression of the ADAM9 prodomain as a potential gene therapy for AD. Furthermore, a more recent publication by Scharfenberg et al. (2019) showed that soluble ADAM10 was able to degrade SAPP $\alpha$ but not full-length APP which implies that ADAM9-mediated shedding of ADAM10 would not only promote amyloidogenic APP processing but also result in decreased levels of the protective sAPP $\alpha$ fragment making the afore mentioned strategy employing the ADAM9 prodomain all the more attractive.

Despite other members of the ADAM family being implicated to varying degrees in $\alpha$ secretase activity, ADAM10 remains the major target for treatments aimed at enhancing protein expression to reduce $A \beta$-peptide production (Peron et al. 2018), with loss-of-function mutations in ADAM10 being associated with late-onset AD (Kim et al. 2009). The potential validity of this approach is supported by data from $A P_{[V 717]}$ transgenic mice overexpressing $A D A M 10$ that show a reduced $A \beta$ plaque load and improved learning and memory as compared to controls (Postina et al. 2004).

However, enhanced ADAM10 levels have been circumstantially associated with increased cancer progression, possibly due to the role of the enzyme in Notch signalling (Gavert et al. 2007; Guo et al. 2012; Yuan et al. 2013). This might partly explain why ADAM10 gene transfer has not been progressed further as a viable AD therapy in humans.

Interestingly, prescribed drugs and small molecular weight molecules that enhance ADAM10 expression [Reviewed in Wetzel et al. (2017)], including fibrates and retinoids, do not increase cancer incidence (Bonovas et al. 2012). In fact, retinoids have shown therapeutic benefits in breast, melanoma and prostate cancers (Tang \& Gudas 2011), and two large studies on fibrates reported an inverse association with liver cancer incidence (Li et al. 2019; lakobishvili et al. 2019). Collectively, these studies suggest that ADAM10 enhancement would not promote cancer in vivo.

Moreover, undesirable effects of enhanced ADAM10 on Notch signalling might be mitigated by specifically targeting the enzyme to lipid rafts (the proposed site of $A \beta$-peptide generation) using a synthetic glycosylphosphatidylinositol (GPI)-anchored form. Indeed, GPIanchored ADAM10 targeted to rafts reduces amyloidogenic APP processing in SH-SY5Y cells (Harris et al. 2009).

While ADAM10 has yet to be tested as a gene therapy, lentiviral-mediated gene transfer of peroxisome proliferator-activated receptor $\gamma$ (PPAR $\gamma)$-coactivator-1 $\alpha$ has been 
shown to increase ADAM17 mRNA levels in APP23 transgenic mice (Katsouri et al. 2016). Interestingly, these ADAM17-overexpressing mice showed fewer $A \beta$ plaques, decreased microglial activation, and improved spatial recognition memory, supporting the potential therapeutic value of this approach.

\subsubsection{Inhibiting $A \beta$-peptide aggregation}

The prion protein ( $\operatorname{PrP})$ is a cell surface glycoprotein with functions in neuronal differentiation, myelin maintenance, and stress handling (Castle \& Gill 2017). Although controversial (Calella et al. 2010; Cissé et al. 2011; Kessels et al. 2010), PrP may partially mediate the toxic effects of A -peptides (Barry et al. 2011; Gimbel et al. 2010; Kudo et al. 2012; Laurén et al. 2009), by acting as a cell surface receptor [Reviewed in (Salazar \& Strittmatter 2017)]. ADAM10 is partly responsible for PrP shedding from the cell membrane, producing a soluble form (Taylor et al. 2009) which, in addition to preventing the toxicity mediated by membrane-bound PrP, also interferes with $A \beta$-peptide aggregation and neurotoxicity (Altmeppen et al. 2013; Nieznanski et al. 2012). Furthermore, PrP cleavage by ADAM10/ADAM17 yields an N-terminal fragment (N1) (Vincent et al. 2001), that binds A oligomers to inhibit fibrillisation (in vitro) and attenuate memory deficits in mice (Fluharty et al. 2013). Gene transfer of either soluble PrP or N1 has yet to be examined but may provide a therapeutic option for $A D$ by preventing PrP-mediated neurotoxicity of $A \beta$-peptides and reducing $A \beta$-peptide accumulation. Furthermore, upregulating ADAM10/ADAM17 (section 2.1.1), might also alleviate AD pathology through both the shedding of membrane bound $\operatorname{Pr} P$ and the generation of the neuroprotective N1 fragment, independent of any effects on $A \beta$ peptide production.

Finally, there is some limited circumstantial evidence to suggest that the overexpression of various heat shock proteins (HSPs) might be beneficial in the treatment of Alzheimer's disease. HSPs can interact with A $\beta$-peptides to prevent their aggregation, and can also inhibit tau aggregation (Dou et al. 2003; Wilhelmus et al. 2007). HSP70 and HSP90 are the most studied HSPs in AD, and HSP70 levels are elevated in AD (Koren et al. 2009; Son et al. 2015). However, AD studies have predominantly researched HSP inhibitors [Reviewed in Campanella et al. (2018)]. This may be due to the observed upregulation of HSP70 in AD brains and the possibility of defective chaperones promoting disease progression rather than attenuating it (Marino Gammazza et al. 2016). While gene therapy for overexpression of specific HSPs may provide a means of preventing $A \beta$-peptide accumulation, we first require a deeper understanding of HSP individual and collective functions in AD pathogenesis.

\subsubsection{Enhancing $A \beta$-peptide degradation and clearance}

Just as the failure of BACE1 inhibitor clinical trials has exemplified the need for alternative strategies to reduce $A \beta$-peptide generation, the need for alternative strategies for the post-generation elimination of these peptides is exemplified by the failure of multiple anti-amyloid antibody clinical trials (Reviewed in Aisen et al. 2020). In 2019, Biogen announced the termination of two clinical trials of the anti-A $\beta$ peptide monoclonal antibody aducanumab based on a lack of benefit or 'futility'. Biogen is currently working with the U.S. Food and Drug Administration (FDA) for regulatory approval of the drug based on subsequent extended analyses that purported to show a slowing of cognitive decline in participants who 
were given a higher dose over a longer period of time. However, clinical trial failures in recent years of multiple other anti-amyloid antibodies such as gantenerumab and crenezumab (both Roche), solanezumab and donanemab (both Eli Lilly) and BAN 2401 (Eisai) does not bode well for this therapeutic approach despite the very recent attempts to resurrect some of these drugs based on marginal effects in participant sub-cohorts. There is, therefore, an immediate need for alternative approaches for the elimination of $A \beta$-peptides from the brain. This need may well be met through the gene therapy-mediated enhancement of proteins that either degrade or facilitate the clearance of $A \beta$-peptides.

$A \beta$-peptide levels are tightly regulated by an array of proteases (Saido \& Leissring 2012), amongst which the zinc metalloendopeptidase, neprilysin (NEP), is responsible for most A $\beta$-peptide degradation (Howell et al. 1995). Consistent with NEP being a rate-limiting enzyme in A $\beta$-catabolism (Takaki et al. 2000), reduced NEP expression is associated with increased $A \beta$ plaque burden in post-mortem AD brains (Grimm et al. 2013). Conversely, herpes simplex virus (HSV), lentiviral and adeno-associated virus (AAV)-mediated NEP gene transfer into APP transgenic mouse models has been shown to reduce A $\beta$-peptide deposition, IL-6 levels, astrocyte activation and improves memory function (El-Amouri et al. 2008; Hong et al. 2006; Iwata et al. 2013; Marr et al. 2003; Spencer et al. 2008). Collectively, these studies provide convincing preclinical evidence for direct overexpression of NEP in AD treatment.

In parallel to NEP, zinc metalloendopeptidases endothelin converting enzymes (ECE)1 and -2 are also involved in $A \beta$ catabolism (Eckman et al. 2001). Individuals homozygous for the C338A polymorphism, that enhances ECE1 promoter activity, have a lower risk of AD (Funalot et al. 2004). Accordingly, upregulation of ECE1 via intracranial administration using a recombinant AAV reduced total A $\beta$-peptide levels in the brains of APP/PS1 mice by $50 \%$ (Carty et al. 2008). The potential effects of ECE1 gene transfer on neuroinflammation or memory impairment were not examined, and these certainly warrant further investigation.

$A \beta$-peptide clearance across the blood-brain barrier (BBB) into the bloodstream is mediated by apolipoprotein $E$ (ApoE) (Kline 2012). In the brain, ApoE is primarily expressed by astrocytes (Grehan et al. 2001). There are three common ApoE isoforms; ApoE2 (Cys112, Cys158), ApoE3 (Cys112, Arg158), and ApoE4 (Arg112, Arg158) (Rall et al. 1982). ApoE4 increases the risk of $A D$ in heterozygous carriers 2-3-fold, and 14-fold in homozygous individuals, while the ApoE2 allele reduces risk, with $A P O E$ genotype being a strong risk factor for AD (Farrer et al. 1997). Lin et al. (2018) used CRISPR/Cas9 gene editing to create isogenic induced pluripotent stem cell (iPSC) lines homozygous for APOE4 from unaffected parental $A P O E 3$ cells. Neurons derived from the former iPSCs exhibited enhanced $A \beta$-peptide secretion relative to the parental cells whilst similarly derived astrocytes exhibited a compromised uptake of A $\beta$-peptides. Microglial cells derived from the edited iPSCs also exhibited a relative decrease in $A \beta$-peptide uptake and increased inflammatory gene activations. Conversely, the authors also observed that converting $A P O E 4$ to $A P O E 3$ in brain cell types derived from sporadic AD iPSCs attenuated multiple AD-related pathologies. Additional studies using similar CRISPR/Cas9 editing in iPSC-derived neurons seem to indicate that a toxic gain of function of APOE4 is responsible for AD-related pathology as such changes can largely be ameliorated following editing to APOE3 (Wang et al. 2018 and Wadhwani et al. 2019). 
Whilst gene editing to ameliorate the toxic effects of ApoE4 holds promise and is currently progressing to preclinical models, the fact that ApoE2 appears to be protective against the development of $A D$ and is most effective at clearing $A \beta$-peptides from the brain (Castellano et al. 2011) has already led to the investigation of ApoE2 gene transfer in preclinical models of $A D$. In a first study, lentivirus-driven expression of ApoE2 in PDAPP transgenic mice reduced total A $\beta$-peptide burden when compared to GFP and ApoE4 controls (Dodart et al. 2005). More recently, AAV-driven expression of ApoE2 was shown to maintain synaptic density in APP/PS1 mice (Hudry et al. 2013) and AAV-mediated enhancement of ApoE2 in PDAPP mice also reduced ApoE4-associated A $\beta$-peptide pathology, dependent on ApoE2 expression and pre-existing amyloid pathology (Zhao et al. 2016). As intracisternal administration is the optimal method for AAV-mediated gene delivery in non-human primates (Rosenberg et al. 2018), a phase I clinical trial was initiated in 2019, with an ApoE2-expression AAV vector administered intracisternally to 15 ApoE4 homozygous individuals (NCT03634007).

\subsubsection{Decreasing tau phosphorylation}

A complementary approach to reducing $A \beta$-peptide accumulation is the promotion of tau dephosphorylation by serine/threonine phosphatases. The potential importance of such an approach is underlined by several recent publications identifying tau phosphorylated at threonine-217 ( $p$-tau217) as a potential biomarker for AD. Indeed both p-tau217 and ptau181 levels have been reported to increase as early as two decades before the occurrence of aggregated tau pathology (Barthélemy et al. 2020) but the former, when quantified in cerebrospinal fluid, performs better as an AD biomarker (Janelizde et al. 2020). Furthermore, plasma p-tau217 has recently been shown to increase in early AD (Mattsson-Carlgren et al. 2020) and to effectively discriminate the disease from other neurodegenerative diseases (Palmqvist et al. 2020).

Protein phosphatase $2 \mathrm{~A}$ (PP2A) accounts for $\sim 70 \%$ of tau dephosphorylation activity (Liu et al. 2005a), which is decreased by $\sim 30 \%$ in AD brains (Gong et al. 1995), consistent with reduced PP2A mRNA levels in the hippocampus of AD patients (Vogelsberg-Ragaglia et al. 2001). Mouse studies have demonstrated that starvation-induced PP2A inhibition contributes to tau hyperphosphorylation even when tau kinases such as GSK-3 $\beta$ are inhibited (Planel et al. 2001). Therefore, upregulation of PP2A, rather than inhibition of tau kinases, could offer treatment options for AD.

PP2A activity is modulated by heat-stable inhibitors $1\left(I_{1} P P 2 A\right)$ and $2\left(I_{2} P P 2 A\right)$ with differential efficacy at distinct tau phosphorylation sites (Li et al. 1995; Tsujio et al. 2005). Lentiviral vectors expressing ${ }_{2} P P 2 A$ siRNA were designed to enhance PP2A activity in $A D$ patients. Hippocampal injection of $\mathrm{I}_{2} \mathrm{PP} 2 \mathrm{~A}$ siRNA reduced tau hyperphosphorylation at multiple residues, decreased GSK-3 $\beta$ activation, improved neuronal spine density, and rescued memory deficits in human tau-transgenic mice (Zhang et al. 2014).

However, PP2A has diverse substrates, impacting on cellular functions such as $\beta$ catenin signalling, p53 tumour suppressor activity, and c-Myc accumulation [Reviewed in Virshup and Shenolikar (2009)]. Thus, while the side-effects of unregulated PP2A expression 
are unknown, they could be extensive. Further research into PP2A and other phosphatase isoforms specifically involved in tau dephosphorylation is required (Sontag \& Sontag 2014).

\subsubsection{Enhancing tau clearance}

Reducing hyperphosphorylated tau may also be achieved through increasing clearance, through proteolytic and degradative mechanisms. Studies in vitro have demonstrated monomeric tau cleavage by the proteases thrombin, calpain, and puromycinsensitive aminopeptidase (Khlistunova et al. 2006; Liu et al. 2011; Sengupta et al. 2006). However, several tau proteolysis products are themselves toxic (Garg et al. 2011; Khlistunova et al. 2006; Wang et al. 2007), requiring downstream degradation by proteasomal and autophagic machineries to be neutralised.

Tau can also be cleared by autophagy (Wang \& Mandelkow 2012). Notably, prelysosomal autophagic vacuoles are abundant in $A D$ brains, suggesting that, whilst autophagy is induced in $A D$, lysosomal maturation is impaired, thereby potentially preventing the neuroprotective actions of autophagy in respect of tau clearance (Nixon et al. 2005). Inducing autophagy thus appears to be a potential treatment option that warrants further investigation. Using gene therapy, overexpression of autophagy modulators has been successfully achieved in rodent models [Reviewed in Levine et al. (2015)]. For example, direct overexpression of transcription factor EB (TFEB), by injection of an AAV-TFEB vector in the substantia nigra of PD rats, led to TFEB expression and increased mRNA levels of lysosomal markers in dopaminergic neurons, suggesting increased activity of the autophagy-lysosomal pathway (Decressac et al. 2013). Importantly, the expression of lysosomal markers suggests progression of autophagy through to the degradation stage, implying that TFEB gene transfer might promote tau degradation in AD.

Finally, gene therapy mediated-overexpression of parkin, a protein responsible for trafficking of mitochondria to the perinuclear region for autophagy (Vives-Bauza et al. 2010), has been trialled preclinically for AD. 3xTg-AD transgenic mice administered with a lentiviral vector for parkin overexpression exhibited increases in autophagy-related protein levels three months after injection, and reduced $A \beta$-peptide levels (Khandelwal et al. 2011).

Numerous studies in other diseases demonstrate that promoting autophagy is both possible and efficacious (Levine et al. 2015; Byun et al. 2017). However, since autophagy contributes to cell death further research is required to prove the safety of autophagy inducers in AD (Levine et al. 2015).

\subsection{Gene therapies that modulate neuroinflammation as potential treatments for AD}

\subsubsection{Anti-inflammatory cytokines}

A critical component of neuroinflammation in the AD-afflicted brain is the production of pro-inflammatory cytokines by activated microglia and astrocytes. However, the role of anti-inflammatory cytokines in AD pathology is more ambiguous (Domingues et al. 2017). For example, short-term AAV-mediated expression of the anti-inflammatory cytokine IL-4 in the TgCRND8 transgenic mouse model exacerbated A $\beta$-peptide deposition (Chakrabarty et al. 2012), but long-term expression in APP/PS1 mice significantly reduced microglial 
accumulation, astrogliosis, and AB-peptide load (Kiyota et al. 2010). Similarly, AAV-mediated gene delivery of murine IL-10 in APP/PS1 mice suppressed astrogliosis, enhanced neurogenesis, and rescued spatial learning deficits (Kiyota et al. 2012). However, a complex relationship between IL-10 levels and AD-related pathology may exist, as deficiency of the protein in APP/PS1 mice was shown to enhance microglial phagocytosis of A $\beta$-peptide and rescued behavioural impairment (Guillot-Sestier et al. 2015). This suggests a complicated relationship between anti-inflammatory cytokine levels and $A D$ relevant pathology, which may be independent of their effects on $A \beta$-peptide. Further research is required to characterise the mechanisms underlying cytokines as a potential therapy in $A D$.

\subsubsection{TREM2}

Triggering receptor expressed on myeloid cells 2 (TREM2) is a transmembrane receptor expressed on myeloid cells including microglia (Colonna \& Wang 2016; Schmid et al. 2002). TREM2 stimulation in mice primary microglial cultures increases phagocytosis while reducing the expression of the proinflammatory cytokines TNF $\alpha$ and IL-1 (Takahashi et al. 2005). The R47H mutation in TREM2, which may cause a decrease in mRNA levels (ChengHathaway et al. 2018), increases the risk of late-onset AD 2- to 3-fold (Carmona et al. 2018). Interestingly, overexpression of TREM2 via lentiviral gene transfer in APP/PS1 mice significantly reduced $A \beta$ plaque density, lowered levels of proinflammatory cytokines, and improved spatial memory (Jiang et al. 2014). This study highlights the potential of TREM2 gene therapy in $A D$, but further research is required.

\subsection{Gene therapies modulating neurotrophic and neuroprotective factors as potential treatments for AD}

\subsection{1. $\quad \mathrm{SAPP} \alpha$}

SAPP $\alpha$, generated via the non-amyloidogenic proteolysis of APP, has been implicated in neurogenesis, brain development and plasticity [Reviewed in Dar and Glazner (2020)]. The neuroprotective actions of SAPP $\alpha$ in vivo include enhancement of neuronal survival, protection from ROS and decreased glutamate-mediated excitotoxicity (Araki et al. 1991; Goodman \& Mattson 1994; Mattson et al. 1993). Furthermore, evidence suggests that sAPP $\alpha$ inhibits BACE1, theoretically reducing amyloidogenic APP processing (Obregon et al. 2012). Gene transfer of $\triangle A P P \alpha$, using an AAV vector, has been examined in APP/PS1 transgenic mice. Direct overexpression of $s A P P \alpha$ in these mice partially reduced $A \beta$ burden, improved synaptic plasticity and rescued spatial reference memory deficits. An increase in microglia recruitment to amyloid plaques was also observed, indicating the possibility of increased $A \beta$-peptide phagocytosis (Fol et al. 2016). No further studies utilising gene transfer for overexpression of SAPPa have been reported.

\subsubsection{Neurotrophins}

Neurotrophins are growth factors important for the proliferation, survival, differentiation and migration of neurons (Kerschensteiner et al. 2003). Additionally, they play a role in development and synaptic plasticity (Ledda \& Paratcha 2016). The first of these to be discovered, nerve growth factor (NGF) (Levi-Montalcini \& Angeletti 1963), promotes the survival of cholinergic neurons following injury (Aloe et al. 2015). This is particularly 
interesting given the degeneration of cholinergic neurons in $A D$, the role of this neuronal subtype in the cognitive symptoms of the disorder and the fact that drugs targeting this system are effective in treating symptoms (Whitehouse et al. 1981; Whitehouse et al. 1982). Therefore, NGF has been implicated as a therapy for $A D$ as a means of preserving cholinergic neurotransmission. Gene transfer of NGF is a widely studied topic, with many preclinical studies (Bishop et al. 2008; Blesch et al. 2005; Fischer et al. 1987; Kordower et al. 1994)[Reviewed in Tuszynski (2007)] and several clinical trials being undertaken. The results of the first clinical trial for NGF gene therapy were reported in 2005 (NCT00017940), following ex vivo delivery of NGF to eight patients with early-stage $A D$; the rate of cognitive decline in patients was slowed with no adverse effects (Tuszynski et al. 2005). A second phase I clinical trial (NCT00087789) demonstrated the safety of AAV-mediated NGF delivery, in addition to a possible dose-dependent reduction in cognitive decline (Rafii et al. 2014). Post-mortem examination of brains from patients in both studies identified cholinergic axonal sprouting in sites of NGF delivery, demonstrating that degenerating neurons can still respond to growth factors (Tuszynski et al. 2015). A phase Il trial (NCT00876863) failed to demonstrate significant improvements in primary clinical outcomes (Rafii et al. 2018). However, pathological analysis revealed that, although targeting of the injection was accurate in most cases, the limited spread of AAV-NGF from the injection site prevented NGF from reaching cholinergic neurons (Castle et al. 2020).

A second neurotrophin, brain-derived neurotrophic factor (BDNF), partly elicits its effects through the modulation of neuroinflammatory processes. BDNF overexpression decreases levels of the proinflammatory cytokine TNF- $\alpha$ whilst increasing levels of the antiinflammatory cytokines IL-4, IL-10, and IL-11 (Makar et al. 2009). BDNF is synthesised in many brain regions, including the entorhinal cortex, where it is anterogradely trafficked to the hippocampus (Leal et al. 2017). Protein levels of BDNF are lowered in the entorhinal cortex and hippocampus of the AD-afflicted brain (Hock et al. 2000; Narisawa-Saito et al. 1996). Several studies have investigated BDNF gene therapy in models of AD. Nagahara et al. demonstrated that lentiviral-mediated gene transfer of BDNF to J20 transgenic mice reversed synapse loss and memory impairment independent of effects on $A \beta$-peptide load, with similar effects being observed in rat and primate models (Nagahara et al. 2009). Hippocampal administration, mediated by a Sendai viral (SeV) vector, to Tg2576 transgenic mice confirmed these findings (Iwasaki et al. 2012). The former study was replicated in younger mice with earlier administration of BDNF shown to prevent neuronal loss, with effects being independent of $A \beta$-peptide load (Nagahara et al. 2013). More recently, magnetic resonance imaging has been used to guide AAV-BDNF delivery to the entorhinal cortex of non-human primates to maximise targeted expression. Such delivery elevated BDNF labelling in the hippocampal dentate gyrus, but functional and behavioural consequences were not reported (Nagahara et al. 2018). In addition to these targeted and selective BDNF manipulations, the indirect enhancement of BDNF expression by gene therapy has also been investigated; increasing levels of CREB (cyclic adenosine monophosphate-response element binding protein) binding protein (CBP) via lentiviral delivery induced BDNF expression and rescued the learning and memory impairment in 3xTg-AD mice (Caccamo et al. 2010). 
Collectively, these results implicate direct or indirect BDNF overexpression as a valid candidate for AD. Importantly, MRI-guided injection could prevent inaccurate administration and improve the limited spread that caused the phase II clinical trial failure of NGF.

\subsubsection{Progranulin}

Progranulin is a trophic factor that promotes neuronal development, survival and neurite outgrowth (Van Damme et al. 2008), in addition to modulating neuroinflammation (Yin et al. 2010). Mutations in the GRN gene encoding progranulin are strongly associated with frontotemporal dementia (Mackenzie et al. 2006; Yu et al. 2010) and are also a risk factor for AD (Perry et al. 2013). P301L tau transgenic mice hemizygous for GRN exhibited enhanced tau phosphorylation (Hosokawa et al. 2015), although introduction of the GRN hemizygote into APP transgenic mice actually decreased A $\beta$-peptide accumulation (Hosokawa et al. 2018).

Administration of GRN using AAV-mediated gene therapy reduced microgliosis and improved lysosomal abnormalities in transgenic mouse models of frontotemporal dementia (Arrant et al. 2018). AAV-GRN has recently received approval to enter clinical trials for frontotemporal dementia (Prevail Therapeutics 2020). Extending this gene therapy for AD may, therefore, prove beneficial through decreasing both tau hyperphosphorylation and neuroinflammation.

\subsubsection{Glucagon-like peptide 1 (GLP1) signalling}

GLP-1 is an incretin hormone primarily synthesised in the gut and released into the bloodstream after food intake (Yildirim Simsir et al. 2018). In the brain, GLP-1 is a growth factor that promotes survival, proliferation, and repair whilst inhibiting apoptosis (Perry \& Greig 2004; Sharma et al. 2014). On binding to its receptor, activation of the downstream signalling pathway facilitates insulin signalling and culminates in inhibition of GSK-3 $\beta$ (Mussmann et al. 2007).

Many studies have demonstrated the potential neuroprotective roles of GLP-1 in AD [Reviewed in Yildirim Simsir et al. (2018)]. For example, inhibition of GSK-3 $\beta$ by GLP-1 reduces age-dependent tau hyperphosphorylation in a diabetic transgenic mouse model (Ma et al. 2015). GLP-1 treatment reduces intracellular A $\beta$-peptide in PC12 cells and protects primary cultured neurons from $A \beta$-induced damage (Perry et al. 2003). In APP/PS1 mice, Liraglutide, a GLP-1 agonist, reduced $A \beta$ plaque load and rescued learning and memory impairment (McClean et al. 2011). Similarly, another GLP-1 agonist, Lixisenatide, reduced A $\beta$-peptide load, NFTs and neuroinflammation in APP/PS1/tau mice (Cai et al. 2018). This reduction in neuroinflammation may not solely be $A \beta$ - and tau-dependent, as GLP-1 reduces IL-1 $\beta$ mRNA expression, microglial activation, and oxidative damage in vitro and in vivo (Iwai et al. 2006; Spielman \& Klegeris 2014; Teramoto et al. 2011).

While safe and efficacious GLP-1 drugs are currently available for the treatment of type II diabetes mellitus (TIIDM), disadvantages include long-term compliance issues and systemic side effects. Selective overexpression of GLP-1 in the CNS may, therefore, present a novel multi-modal therapy for AD. Gene transfer of GLP-1 has yet to be reported in in vivo models of $A D$, although it has been examined in relation to TIIDM (Tasyurek et al. 2014). Whilst these studies focused on systemic expression of GLP-1, as opposed to selective 
neuronal expression, they validate the possibility of sustained GLP-1 expression via gene therapy. By modifying the promoter and/or route of administration, gene transfer of GLP-1 selectively to neurons may exhibit neuroprotective effects in AD transgenic mouse models. Although this remains to be adequately tested.

\subsection{Enhancing proteins that regulate oxidative stress}

Antioxidants previously studied in relation to $A D$ include glutathione, carotenoids, vitamin C, vitamin E, and $\alpha$-lipoic acid (Mirończuk-Chodakowska et al. 2018). The effect of orally administered vitamin $E$ on $A D$ has been examined in many clinical trials over 20 years (Sano et al. 1997), although results remain inconclusive (Browne et al. 2019).

Nuclear factor E2-related factor 2 (Nrf2) binds to the antioxidant response element (ARE) to promote transcription of anti-oxidative genes (Liu et al. 2017) and several preclinical studies support the therapeutic potential of modulating Nrf2. For example, administration of sulforaphane, an Nrf2 activator, in PS1V97L-Tg mice decreased amyloid pathology and rescued cognitive deficits (Tian et al. 2019). Moreover, lentiviral-mediated gene transfer of $\mathrm{Nrf2}$ to the hippocampus of APP/PS1 mice reduced astrocytosis and improved spatial learning (Kanninen et al. 2009). Nrf2 has also been implicated as a negative regulator BACE1 transcription in mouse embryonic fibroblasts (Bahn et al. 2019), suggesting that upregulation could provide a multi-mechanistic treatment for $A D$ involving both reduced oxidation and modified amyloid processing. Further upstream, $\alpha$-lipoic acid may act through several mechanisms to activate Nrf2 (Brandes \& Gray 2020). Gene transfer of $\alpha$-lipoic acid synthetase, an enzyme involved in $\alpha$-lipoic acid biosynthesis, may also be a potential treatment option. However, the bioavailability of many antioxidants makes antioxidant gene therapy in $A D$ an understudied area.

\section{Gene transfer technologies can allow specific and highly regulated protein expression}

A range of preclinical and, to a lesser extent, clinical studies have already examined gene therapy strategies in the treatment of AD. However, there are clear safety considerations to be made before such strategies reach the clinical stage. One of the key concerns in this respect is host immune response to the therapy both in terms of an immediate adverse reaction and in terms of an adaptive immune response resulting in the production of therapy neutralizing antibodies (reviewed in Shirley et al. 2020). In the case of Alzheimer's disease, such reactions may, to some extent, be mitigated by stereotactic therapy injection although, for obvious reasons, this is far from ideal in the clinic. Gene therapy may also cause severe toxicity if the expression level of the transgene is not sufficiently regulated or expressed in off-target cells/tissue. Related toxic consequences in non-human primates have previously included ataxia, impaired ambulation, proprioceptive deficits and damaged dorsal root ganglia (Hinderer et al. 2018). In addition, insertional mutagenesis and genotoxicity are likely to be concerns when certain transgenes are injected with high-dose vectors (Chandler et al. 2017). Nonetheless, gene therapy for the treatment of AD remains an attractive and topical proposition and, to some extent, some of these problems can already be mitigated as discussed below. 


\subsection{Specificity}

Most potential gene therapies for $A D$ use direct injection into the brain to ensure region specificity of expression. Neuronal-specific promoters can also be used for targeted gene expression. For example, the neuron-specific enolase (NSE) promoter and the plateletderived growth factor promoter drive gene expression exclusively in neurons, with expression lasting for over two months in the adult rat (Peel et al. 1997). Similarly, the neuronalspecificity of the human synapsin-1, $\alpha$-tubulin and calcium/calmodulin-dependent protein kinase Il $\alpha$ (CaMKIl $\alpha$ ) promoters have previously been described (Kügler et al. 2003; Mayford et al. 1996; Gloster et al. 1994). Additionally, all five of these promoters have been successfully fused to the cytomegalovirus enhancer to create hybrid promoters with 2- to 4fold increased expression levels relative to the native neuronal-specific promoters (Hioki et al. 2007).

\subsection{Inducible systems}

Conventional gene therapy cannot regulate, or reverse, gene expression once initiated. Uncontrolled systemic gene expression carries a plethora of adverse effects (Liu \& Kirn 2007). In an attempt to resolve such issues, inducible gene expression systems have been developed [for review see Kallunki et al. (2019)].

The most widely used is the tetracycline (Tet)-inducible expression system, which has the advantage that tetracycline derivatives are prevalent in clinical practice (Naidoo \& Young 2012). The system has three possible configurations: (1) repression-based, (2) Tet-off, and (3) Tet-on (Kallunki et al. 2019). In the latter of these, presence of the drug activates transcription of the target gene. This configuration is advantageous in gene therapy as the tetracycline derivative can be discontinued when gene overexpression is no longer required or adverse effects occur. The system has been further optimised to ensure negligible "leakiness" in the absence of the drug (Shaikh \& Nicholson 2006; Zhou et al. 2006).

The use of inducible expression systems for disease treatment has been validated in cancer therapy where systemic administration of IL-12 to advanced renal cell carcinoma patients had previously resulted in severe toxicity and two deaths (Leonard et al. 1997). Utilising the RheoSwitch Therapeutic System ${ }^{\circledR}$, which uses veledimex as the activator ligand, results in tumour-specific inducible IL-12 expression that is well tolerated in both preclinical studies and Phase I clinical trials for glioblastoma and advanced melanoma (Barrett et al. 2018; Linette et al. 2013; Schwartzentruber et al. 2011).

In combination with a cell or tissue-specific promoter and, possibly, local injection, inducible systems might mitigate adverse events from more widespread unregulated overexpression of the therapeutic protein. For example, the forebrain-specific CaMKIl $\alpha$ promoter used within a Tet-inducible system permits inducible and reversible expression specifically within neurons in mice (Michalon et al. 2005). Similarly, tamoxifen-inducible expression driven by the NSE promoter resulted in exclusive cerebellar granule cell expression in mice (Pohlkamp et al. 2014). Therefore, integration of inducible systems and neuronal- 
specific promoters into future research should permit controlled expression of therapeutic proteins by gene therapy in $A D$, which may improve success in clinical trials.

\section{Concluding remarks}

Despite the large number of candidate treatments previously developed for $A D$, many drugs have failed in clinical testing. While gene therapy itself is not a new concept, our expanding knowledge of $A D$ aetiology and recent developments in gene therapy systems provides new promise for this currently incurable disease. Here, we have discussed several therapeutic proteins that remain to be validated using gene therapy. The range of putative therapeutic target proteins will likely increase as our understanding of AD further develops. Whilst further preclinical validation of gene therapy-mediated protein overexpression is needed before testing in clinical trials, the in vitro and in vivo studies described herein demonstrate the feasibility of gene therapy as a future treatment strategy for AD. 


\section{References}

Aisen, P., Cummings, J., Doody, R. et al. (2020) The future of anti-amyloid trials. JPAD 7, 146-151.

Aloe, L., Rocco, M. L., Balzamino, B. O. and Micera, A. (2015) Nerve Growth Factor: A Focus on Neuroscience and Therapy. Curr Neuropharmacol 13, 294-303.

Alonso, A. C., Li, B., Grundke-lqbal, I. and Iqbal, K. (2006) Polymerization of hyperphosphorylated tau into filaments eliminates its inhibitory activity. Proc Natl Acad Sci U S A 103, 8864-8869.

Alonso, A. C., Zaidi, T., Grundke-lqbal, I. and Iqbal, K. (1994) Role of abnormally phosphorylated tau in the breakdown of microtubules in Alzheimer disease. Proc Natl Acad Sci U S A 91, 55625566.

Altmeppen, H. C., Prox, J., Puig, B. et al. (2013) Roles of endoproteolytic $\alpha$-cleavage and shedding of the prion protein in neurodegeneration. The FEBS Journal 280, 4338-4347.

Anderson, J. P., Esch, F. S., Keim, P. S. et al. (1991) Exact cleavage site of Alzheimer amyloid precursor in neuronal PC-12 cells. Neuroscience Letters 128, 126-128.

Annunziata, I., Patterson, A., Helton, D. et al. (2013) Lysosomal NEU1 deficiency affects amyloid precursor protein levels and amyloid- $\beta$ secretion via deregulated lysosomal exocytosis. Nat. Comm. 4, 2734.

Araki, W., Kitaguchi, N., Tokushima, Y. et al.(1991) Trophic effect of beta-amyloid precursor protein on cerebral cortical neurons in culture. Biochem Biophys Res Commun 181, 265-271.

Arbor, S.C., LaFontaine, M. and Cumbay, M. (2016) Amyloid-beta Alzheimer targets - protein processing, lipid rafts, and amyloid-beta pores. The Yale Journal of Biology and Medicine 89, 5-21.

Areosa, S. A., Sherriff, F. and McShane, R. (2005) Memantine for dementia. Cochrane Database Syst Rev, Cd003154.

Arrant, A. E., Onyilo, V. C., Unger, D. E. and Roberson, E. D. (2018) Progranulin Gene Therapy Improves Lysosomal Dysfunction and Microglial Pathology Associated with Frontotemporal Dementia and Neuronal Ceroid Lipofuscinosis. J Neurosci 38, 2341-2358.

Bahn, G., Park, J.-S., Yun, U. J. et al.(2019) NRF2/ARE pathway negatively regulates BACE1 expression and ameliorates cognitive deficits in mouse Alzheimer's models. Proceedings of the National Academy of Sciences 116, 12516.

Barrett, J. A., Cai, H., Miao, J. et al. (2018) Regulated intratumoral expression of IL-12 using a RheoSwitch Therapeutic System $\left({ }^{\circledR}\right)\left(\mathrm{RTS}\left({ }^{\circledR}\right)\right)$ gene switch as gene therapy for the treatment of glioma. Cancer Gene Ther 25, 106-116.

Barry, A. E., Klyubin, I., Mc Donald, J. M. et al. (2011) Alzheimer's disease brain-derived amyloid- $\beta$ mediated inhibition of LTP in vivo is prevented by immunotargeting cellular prion protein. $J$ Neurosci 31, 7259-7263.

Bathélemy, N., Li, Y., Joseph-Mathurin, N. et al. (2020) A soluble phosphorylated tau signature links tau, amyloid and the evolution of stages of dominantly inherited Alzheimer's disease. Nat. Med. 26, 398-407.

Beach, T. G. and McGeer, E. G. (1988) Lamina-specific arrangement of astrocytic gliosis and senile plaques in Alzheimer's disease visual cortex. Brain Research 463, 357-361.

Bishop, K. M., Hofer, E. K., Mehta, A. et al. (2008) Therapeutic potential of CERE-110 (AAV2-NGF): Targeted, stable, and sustained NGF delivery and trophic activity on rodent basal forebrain cholinergic neurons. Experimental Neurology 211, 574-584.

Blesch, A., Conner, J., Pfeifer, A. et al. (2005) Regulated lentiviral NGF gene transfer controls rescue of medial septal cholinergic neurons. Mol Ther 11, 916-925.

Bonovas, S., Nikolopoulos, G. K. and Bagos, P. G. (2012) Use of Fibrates and Cancer Risk: A Systematic Review and Meta-Analysis of 17 Long-Term Randomized Placebo-Controlled Trials. PLOS ONE 7, e45259.

Braak, H. and Braak, E. (1991) Neuropathological stageing of Alzheimer-related changes. Acta Neuropathol 82, 239-259. 
Brandes, M. S. and Gray, N. E. (2020) NRF2 as a Therapeutic Target in Neurodegenerative Diseases. ASN Neuro 12, 1759091419899782.

Browne, D., McGuinness, B., Woodside, J. V. and McKay, G. J. (2019) Vitamin E and Alzheimer's disease: what do we know so far? Clin Interv Aging 14, 1303-1317.

Byun, S., Lee, E. and Lee, K. W. (2017) Therapeutic Implications of Autophagy Inducers in Immunological Disorders, Infection, and Cancer. Int J Mol Sci 18, 1959.

Cabrales Fontela, Y., Kadavath, H., Biernat, J. et al. (2017) Multivalent cross-linking of actin filaments and microtubules through the microtubule-associated protein Tau. Nat Commun 8, 19811981.

Caccamo, A., Maldonado, M. A., Bokov, A. F., Majumder, S. and Oddo, S. (2010) CBP gene transfer increases BDNF levels and ameliorates learning and memory deficits in a mouse model of Alzheimer's disease. Proc Natl Acad Sci U S A 107, 22687-22692.

Caccamo, A., Oddo, S., Sugarman, M. C., Akbari, Y. and LaFerla, F. M. (2005) Age- and regiondependent alterations in $A \beta$-degrading enzymes: implications for $A \beta$-induced disorders. Neurobiology of Aging 26, 645-654.

Cai, H.-Y., Yang, J.-T., Wang, Z.-J. et al. (2018) Lixisenatide reduces amyloid plaques, neurofibrillary tangles and neuroinflammation in an APP/PS1/tau mouse model of Alzheimer's disease. Biochemical and Biophysical Research Communications 495, 1034-1040.

Calella, A. M., Farinelli, M., Nuvolone, M. et al. (2010) Prion protein and Abeta-related synaptic toxicity impairment. EMBO Mol Med 2, 306-314.

Campanella, C., Pace, A., Caruso Bavisotto, C. et al. (2018) Heat Shock Proteins in Alzheimer's Disease: Role and Targeting. Int J Mol Sci 19, 2603.

Carmona, S., Zahs, K., Wu, E. et al. (2018) The role of TREM2 in Alzheimer's disease and other neurodegenerative disorders. The Lancet Neurology 17, 721-730.

Carty, N. C., Nash, K., Lee, D. et al. (2008) Adeno-associated viral (AAV) serotype 5 vector mediated gene delivery of endothelin-converting enzyme reduces Abeta deposits in APP + PS1 transgenic mice. Mol Ther 16, 1580-1586.

Castellano, J. M., Kim, J., Stewart, F. R. et al. (2011) Human apoE isoforms differentially regulate brain amyloid- $\beta$ peptide clearance. Sci Transl Med 3, 89ra57-89ra57.

Castle, A. R. and Gill, A. C. (2017) Physiological Functions of the Cellular Prion Protein. Front Mol Biosci 4, 19-19.

Castle, M. J., Baltanás, F. C., Kovacs, I. et al. (2020) Postmortem Analysis in a Clinical Trial of AAV2NGF Gene Therapy for Alzheimer's Disease Identifies a Need for Improved Vector Delivery. Human Gene Therapy 31, 415-422.

Chakrabarty, P., Tianbai, L., Herring, A. et al. (2012) Hippocampal expression of murine IL-4 results in exacerbation of amyloid deposition. Molecular neurodegeneration 7, 36-36.

Chandler, R., Sands, M., Venditti, C. (2017) Recombinant adenoassociated viral integration and genotoxicity: insights from animal models. Human Gene Therapy 28, 314-322.

Cheng-Hathaway, P. J., Reed-Geaghan, E. G., Jay, T. R. et al. (2018) The Trem2 R47H variant confers loss-of-function-like phenotypes in Alzheimer's disease. Molecular neurodegeneration 13, 29-29.

Chow, V. W., Mattson, M. P., Wong, P. C. and Gleichmann, M. (2010) An overview of APP processing enzymes and products. Neuromolecular Med 12, 1-12.

Cissé, M., Sunyach, C., Lefranc-Jullien, S. et al. (2005) The disintegrin ADAM9 indirectly contributes to the physiological processing of cellular prion by modulating ADAM10 activity. Journal of Biological Chemistry 280, 40624-40631.

Cissé, M., Sanchez, P. E., Kim, D. H. et al. (2011) Ablation of cellular prion protein does not ameliorate abnormal neural network activity or cognitive dysfunction in the J20 line of human amyloid precursor protein transgenic mice. J Neurosci 31, 10427-10431.

Colonna, M. and Wang, Y. (2016) TREM2 variants: new keys to decipher Alzheimer disease pathogenesis. Nature Reviews Neuroscience 17, 201-207. 
Dar, N. J. and Glazner, G. W. (2020) Deciphering the neuroprotective and neurogenic potential of soluble amyloid precursor protein alpha (SAPP $\alpha$ ). Cellular and Molecular Life Sciences.

Decressac, M., Mattsson, B., Weikop, P. et al.(2013) TFEB-mediated autophagy rescues midbrain dopamine neurons from $\alpha$-synuclein toxicity. Proc Natl Acad Sci U S A 110, E1817-E1826.

Dodart, J.-C., Marr, R. A., Koistinaho, M. et al. (2005) Gene delivery of human apolipoprotein E alters brain Abeta burden in a mouse model of Alzheimer's disease. Proc Natl Acad Sci U S A 102, 1211-1216.

Domingues, C., da Cruz E Silva, O. A. B. and Henriques, A. G. (2017) Impact of Cytokines and Chemokines on Alzheimer's Disease Neuropathological Hallmarks. Curr Alzheimer Res 14, 870-882.

Dorfman, L. M. and Adams, G. E. (1973) Reactivity of the Hydroxyl Radical in Aqueous Solutions. (U. S. D. o. Commerce ed.).

Dou, F., Netzer, W. J., Tanemura, K. et al. (2003) Chaperones increase association of tau protein with microtubules. Proc Natl Acad Sci U S A 100, 721-726.

DuBoff, B., Götz, J. and Feany, M. B. (2012) Tau promotes neurodegeneration via DRP1 mislocalization in vivo. Neuron 75, 618-632.

Eckman, E. A., Reed, D. K. and Eckman, C. B. (2001) Degradation of the Alzheimer's amyloid beta peptide by endothelin-converting enzyme. J Biol Chem 276, 24540-24548.

El-Amouri, S. S., Zhu, H., Yu, J. et al. (2008) Neprilysin: an enzyme candidate to slow the progression of Alzheimer's disease. The American journal of pathology 172, 1342-1354.

Famer, D., Meaney, S., Mousavi, M. et al. (2007) Regulation of alpha- and beta-secretase activity by oxysterols: cerebrosterol stimulates processing of APP via the alpha-secrtease pathway. Biochem. Biophys. Res. Comm. 359, 46-50.

Farlow, M. (2002) A Clinical Overview of Cholinesterase Inhibitors in Alzheimer's Disease. International Psychogeriatrics 14, 93-126.

Farrer, L. A., Cupples, L. A., Haines, J. L. et al. (1997) Effects of age, sex, and ethnicity on the association between apolipoprotein E genotype and Alzheimer disease. A meta-analysis. APOE and Alzheimer Disease Meta Analysis Consortium. Jama 278, 1349-1356.

Fischer, W., Wictorin, K., Björklund, A. et al. (1987) Amelioration of cholinergic neuron atrophy and spatial memory impairment in aged rats by nerve growth factor. Nature 329, 65-68.

Fluharty, B. R., Biasini, E., Stravalaci, M. et al. (2013) An N-terminal fragment of the prion protein binds to amyloid- $\beta$ oligomers and inhibits their neurotoxicity in vivo. The Journal of biological chemistry $288,7857-7866$.

Fol, R., Braudeau, J., Ludewig, S. et al. (2016) Viral gene transfer of APPs $\alpha$ rescues synaptic failure in an Alzheimer's disease mouse model. Acta Neuropathologica 131, 247-266.

Funalot, B., Ouimet, T., Claperon, A. et al. (2004) Endothelin-converting enzyme-1 is expressed in human cerebral cortex and protects against Alzheimer's disease. Molecular Psychiatry 9, $1122-1128$.

Garg, S., Timm, T., Mandelkow, E. M., Mandelkow, E. and Wang, Y. (2011) Cleavage of Tau by calpain in Alzheimer's disease: the quest for the toxic 17 kD fragment. Neurobiol Aging 32, 1-14.

Gavert, N., Sheffer, M., Raveh, S. et al. (2007) Expression of L1-CAM and ADAM10 in Human Colon Cancer Cells Induces Metastasis. Cancer Research 67, 7703.

Gimbel, D. A., Nygaard, H. B., Coffey, E. E. et al. (2010) Memory impairment in transgenic Alzheimer mice requires cellular prion protein. J Neurosci 30, 6367-6374.

Giraldo, E., Lloret, A., Fuchsberger, T. and Viña, J. (2014) A $\beta$ and tau toxicities in Alzheimer's are linked via oxidative stress-induced p38 activation: protective role of vitamin E. Redox Biol 2, 873-877.

Gloster, A., Wu, W., Speelman, A. et al. (1994) The T alpha 1 alpha-tubulin promoter specifies gene expression as a function of neuronal growth and regeneration in transgenic mice. The Journal of Neuroscience 14, 7319. 
Goate, A., Chartier-Harlin, M. C., Mullan, M. et al. (1991) Segregation of a missense mutation in the amyloid precursor protein gene with familial Alzheimer's disease. Nature 349, 704-706.

Goedert, M., Spillantini, M. G., Jakes, R., Rutherford, D. and Crowther, R. A. (1989) Multiple isoforms of human microtubule-associated protein tau: sequences and localization in neurofibrillary tangles of Alzheimer's disease. Neuron 3, 519-526.

Gong, C. X., Shaikh, S., Wang, J. Z. et al. (1995) Phosphatase activity toward abnormally phosphorylated tau: decrease in Alzheimer disease brain. J Neurochem 65, 732-738.

Goodman, Y. and Mattson, M. P. (1994) Secreted forms of beta-amyloid precursor protein protect hippocampal neurons against amyloid beta-peptide-induced oxidative injury. Exp Neurol 128, 1-12.

Gough, M., Parr-Sturgess, C. and Parkin, E. (2011) Zinc metalloproteinases and amyloid beta-peptide metabolism: the positive side of proteolysis in Alzheimer's disease. Biochemistry Research International 2011, 721463.

Grehan, S., Tse, E. and Taylor, J. M. (2001) Two distal downstream enhancers direct expression of the human apolipoprotein E gene to astrocytes in the brain. J Neurosci 21, 812-822.

Grimm, M. O. W., Mett, J., Stahlmann, C. P. et al. (2013) Neprilysin and A $\beta$ Clearance: Impact of the APP Intracellular Domain in NEP Regulation and Implications in Alzheimer's Disease. Front Aging Neurosci 5, 98-98.

Grundke-Iqbal, I., Iqbal, K., Tung, Y. C. et al. (1986) Abnormal phosphorylation of the microtubuleassociated protein tau (tau) in Alzheimer cytoskeletal pathology. Proc Natl Acad Sci U S A 83, 4913-4917.

Guilloreau, L., Combalbert, S., Sournia-Saquet, A., Mazarguil, H. and Faller, P. (2007) Redox chemistry of copper-amyloid-beta: the generation of hydroxyl radical in the presence of ascorbate is linked to redox-potentials and aggregation state. Chembiochem 8, 1317-1325.

Guillot-Sestier, M.-V., Doty, K. R., Gate, D. et al. (2015) II10 deficiency rebalances innate immunity to mitigate Alzheimer-like pathology. Neuron 85, 534-548.

Guo, J., He, L., Yuan, P. et al. (2012) ADAM10 overexpression in human non-small cell lung cancer correlates with cell migration and invasion through the activation of the Notch1 signaling pathway. Oncol Rep 28, 1709-1718.

Hardy, J. and Allsop, D. (1991) Amyloid deposition as the central event in the aetiology of Alzheimer's disease. Trends in Pharmacological Sciences 12, 383-388.

Harris, B., Pereira, I. and Parkin, E. (2009) Targeting ADAM10 to lipid rafts in neuroblastoma SH-SY5Y cells impairs amyloidogenic processing of the amyloid precursor protein. Brain Res 1296, 203-215.

He, Y., Zheng, M. M., Ma, Y. et al. (2012) Soluble oligomers and fibrillar species of amyloid $\beta$-peptide differentially affect cognitive functions and hippocampal inflammatory response. Biochem Biophys Res Commun 429, 125-130.

Hickman, S. E., Allison, E. K. and El Khoury, J. (2008) Microglial dysfunction and defective betaamyloid clearance pathways in aging Alzheimer's disease mice. J Neurosci 28, 8354-8360.

Hinderer, C., Katz, N., Buza, E. et al. (2018) Severe toxicity in nonhuman primates and piglets following high-dose intravenous administration of an adeno-associated virus vector expressing human SMN. Human Gene Therapy 29, 285-298.

Hioki, H., Kameda, H., Nakamura, H. et al. (2007) Efficient gene transduction of neurons by lentivirus with enhanced neuron-specific promoters. Gene Therapy 14, 872-882.

Hock, C., Heese, K., Hulette, C., Rosenberg, C. and Otten, U. (2000) Region-specific neurotrophin imbalances in Alzheimer disease: decreased levels of brain-derived neurotrophic factor and increased levels of nerve growth factor in hippocampus and cortical areas. Arch Neurol 57, 846-851.

Hong, C. S., Goins, W. F., Goss, J. R., Burton, E. A. and Glorioso, J. C. (2006) Herpes simplex virus RNAi and neprilysin gene transfer vectors reduce accumulation of Alzheimer's disease-related amyloid- $\beta$ peptide in vivo. Gene Therapy $13,1068-1079$. 
Hosokawa, M., Arai, T., Masuda-Suzukake, M. et al. (2015) Progranulin reduction is associated with increased tau phosphorylation in P301L tau transgenic mice. J Neuropathol Exp Neurol 74, 158-165.

Hosokawa, M., Tanaka, Y., Arai, T. et al. (2018) Progranulin haploinsufficiency reduces amyloid beta deposition in Alzheimer's disease model mice. Exp Anim 67, 63-70.

Howell, S., Nalbantoglu, J. and Crine, P. (1995) Neutral endopeptidase can hydrolyze beta-amyloid(140 ) but shows no effect on beta-amyloid precursor protein metabolism. Peptides $16,647-$ 652.

Hudry, E., Dashkoff, J., Roe, A. D. et al. (2013) Gene transfer of human Apoe isoforms results in differential modulation of amyloid deposition and neurotoxicity in mouse brain. Sci Transl Med 5, 212ra161-212ra161.

Hudry, E., Van Dam, D., Kulik, W. et al. (2010) Adeno-associated virus gene therapy with cholesterol 24-hydroxylase reduces the amyloid pathology before or after the onset of amyloid plaques in mouse models of Alzheimer's Disease. Molecular Therapy 18, 44-53.

lakobishvili, Z., Hasin, T., Klempfner, R. et al. (2019) Association of Bezafibrate Treatment With Reduced Risk of Cancer in Patients With Coronary Artery Disease. Mayo Clinic Proceedings 94, 1171-1179.

Iwai, T., Ito, S., Tanimitsu, K., Udagawa, S. and Oka, J. (2006) Glucagon-like peptide-1 inhibits LPSinduced IL-1beta production in cultured rat astrocytes. Neurosci Res 55, 352-360.

Iwasaki, Y., Negishi, T., Inoue, M. et al. (2012) Sendai virus vector-mediated brain-derived neurotrophic factor expression ameliorates memory deficits and synaptic degeneration in a transgenic mouse model of Alzheimer's disease. Journal of Neuroscience Research 90, 981989.

Iwata, N., Sekiguchi, M., Hattori, Y. et al. (2013) Global brain delivery of neprilysin gene by intravascular administration of AAV vector in mice. Scientific Reports 3, 1472.

Janelidze, S., Stomrud, E., Smith, R. et al. (2020) Cerebrospinal fluid p-tau217 performs better than ptau181 as a biomarker of Alzheimer's disease. Nat. Commun. 11, 1683.

Jarrett, J. T., Berger, E. P. and Lansbury, P. T., Jr. (1993) The C-terminus of the beta protein is critical in amyloidogenesis. Ann N Y Acad Sci 695, 144-148.

Jiang, D., Men, L., Wang, J. et al. (2007) Redox reactions of copper complexes formed with different beta-amyloid peptides and their neuropathological [correction of neuropathalogical] relevance. Biochemistry 46, 9270-9282.

Jiang, T., Tan, L., Zhu, X.-C. et al. (2014) Upregulation of TREM2 ameliorates neuropathology and rescues spatial cognitive impairment in a transgenic mouse model of Alzheimer's disease. Neuropsychopharmacology 39, 2949-2962.

Kallunki, T., Barisic, M., Jäättelä, M. and Liu, B. (2019) How to Choose the Right Inducible Gene Expression System for Mammalian Studies? Cells 8, 796.

Kanninen, K., Heikkinen, R., Malm, T. et al. (2009) Intrahippocampal injection of a lentiviral vector expressing Nrf2 improves spatial learning in a mouse model of Alzheimer's disease. Proc Natl Acad Sci U S A 106, 16505-16510.

Katsouri, L., Lim, Y. M., Blondrath, K. et al. (2016) PPARY-coactivator-1 $\alpha$ gene transfer reduces neuronal loss and amyloid- $\beta$ generation by reducing $\beta$-secretase in an Alzheimer's disease model. Proceedings of the National Academy of Sciences 113, 12292-12297.

Kerschensteiner, M., Stadelmann, C., Dechant, G., Wekerle, H. and Hohlfeld, R. (2003) Neurotrophic cross-talk between the nervous and immune systems: Implications for neurological diseases. Annals of Neurology 53, 292-304.

Kessels, H. W., Nguyen, L. N., Nabavi, S. and Malinow, R. (2010) The prion protein as a receptor for amyloid-beta. Nature 466, E3-E5.

Khandelwal, P. J., Herman, A. M., Hoe, H.-S., Rebeck, G. W. and Moussa, C. E. H. (2011) Parkin mediates beclin-dependent autophagic clearance of defective mitochondria and ubiquitinated Abeta in AD models. Hum Mol Genet 20, 2091-2102. 
Khlistunova, I., Biernat, J., Wang, Y. et al. (2006) Inducible expression of Tau repeat domain in cell models of tauopathy: aggregation is toxic to cells but can be reversed by inhibitor drugs. $J$ Biol Chem 281, 1205-1214.

Kim, M., Suh, J., Romano, D. et al. (2009) Potential late-onset Alzheimer's disease-associated mutations in the ADAM10 gene attenuate \{alpha\}-secretase activity. Hum Mol Genet 18, 3987-3996.

Kiyota, T., Ingraham, K. L., Swan, R. J. et al. (2012) AAV serotype 2/1-mediated gene delivery of antiinflammatory interleukin-10 enhances neurogenesis and cognitive function in APP+PS1 mice. Gene Therapy 19, 724-733.

Kiyota, T., Okuyama, S., Swan, R. J. et al. (2010) CNS expression of anti-inflammatory cytokine interleukin-4 attenuates Alzheimer's disease-like pathogenesis in APP+PS1 bigenic mice. FASEB J 24, 3093-3102.

Kline, A. (2012) Apolipoprotein E, amyloid-ß clearance and therapeutic opportunities in Alzheimer's disease. Alzheimers Res Ther 4, 32-32.

Koh, S.-H., Noh, M. Y. and Kim, S. H. (2008) Amyloid-beta-induced neurotoxicity is reduced by inhibition of glycogen synthase kinase-3. Brain Research 1188, 254-262.

Koike, H., Tomioka, S., Sorimachi, H. et al. (1999) Membrane-anchored metalloprotease MDC9 has an $\alpha$-secretase activity responsible for processing the amyloid precursor protein. Biochemical Journal 343, 371-375.

Kordower, J. H., Winn, S. R., Liu, Y. T. et al. (1994) The aged monkey basal forebrain: rescue and sprouting of axotomized basal forebrain neurons after grafts of encapsulated cells secreting human nerve growth factor. Proc Natl Acad Sci U S A 91, 10898-10902.

Koren, J., 3rd, Jinwal, U. K., Lee, D. C. et al. (2009) Chaperone signalling complexes in Alzheimer's disease. J Cell Mol Med 13, 619-630.

Kovac, A., Zilka, N., Kazmerova, Z. et al. (2011) Misfolded Truncated Protein $\tau$ Induces Innate Immune Response via MAPK Pathway. The Journal of Immunology 187, 2732-2739.

Kudo, W., Lee, H.-P., Zou, W.-Q. et al. (2012) Cellular prion protein is essential for oligomeric amyloid- $\beta$-induced neuronal cell death. Hum Mol Genet 21, 1138-1144.

Kumar, D., Ganeshpurkar, A., Kumar, D. et al. (2018) Secretase inhibitors for the treatment of Alzheimer's disease: Long road ahead. European J Med Chem 148, 436-452.

Kügler, S., Kilic, E. and Bähr, M. (2003) Human synapsin 1 gene promoter confers highly neuronspecific long-term transgene expression from an adenoviral vector in the adult rat brain depending on the transduced area. Gene Ther 10, 337-347.

Lanoiselée, H.-M., Nicolas, G., Wallon, D. et al. (2017) APP, PSEN1, and PSEN2 mutations in earlyonset Alzheimer disease: A genetic screening study of familial and sporadic cases. PLOS Medicine 14, e1002270.

Laurén, J., Gimbel, D. A., Nygaard, H. B., Gilbert, J. W. and Strittmatter, S. M. (2009) Cellular prion protein mediates impairment of synaptic plasticity by amyloid-beta oligomers. Nature 457, 1128-1132.

Leal, G., Bramham, C. R. and Duarte, C. B. (2017) Chapter Eight - BDNF and Hippocampal Synaptic Plasticity. In: Vitamins and Hormones, (G. Litwack ed.), Vol. 104, pp. 153-195. Academic Press.

Ledda, F. and Paratcha, G. (2016) Assembly of Neuronal Connectivity by Neurotrophic Factors and Leucine-Rich Repeat Proteins. Front Cell Neurosci 10, 199-199.

Leonard, J. P., Sherman, M. L., Fisher, G. L. et al. (1997) Effects of single-dose interleukin-12 exposure on interleukin-12-associated toxicity and interferon-gamma production. Blood 90, 25412548.

Levi-Montalcini, R. and Angeletti, P. U. (1963) Essential role of the nerve growth factor in the survival and maintenance of dissociated sensory and sympathetic embryonic nerve cells in vitro. Developmental Biology 7, 653-659. 
Levine, B., Packer, M. and Codogno, P. (2015) Development of autophagy inducers in clinical medicine. J Clin Invest 125, 14-24.

Li, I. H., Shih, J.-H., Tsai, C.-S. et al. (2019) Inverse Association of Fibrates and Liver Cancer: A Population-Based Case-Control Study in Taiwan. The Journal of Clinical Pharmacology 59, 1170-1176.

Li, M., Guo, H. and Damuni, Z. (1995) Purification and Characterization of Two Potent Heat-Stable Protein Inhibitors of Protein Phosphatase 2A from Bovine Kidney. Biochemistry 34, 19881996.

Lin, Y., Seo, J., Gao, F. et al. (2018) APOE4 causes widespread molecular and cellular alterations associated with Alzheimer's disease phenotypes in human iPSC-derived brain cell types. Nature 98, 1141-1154.

Linette, G. P., Hamid, O., Whitman, E. D. et al. (2013) A phase I open-label study of Ad-RTS-hIL-12, an adenoviral vector engineered to express hIL-12 under the control of an oral activator ligand, in subjects with unresectable stage III/IV melanoma. Journal of Clinical Oncology 31, 30223022.

Liu, F., Grundke-Iqbal, I., Iqbal, K. and Gong, C. X. (2005a) Contributions of protein phosphatases PP1, PP2A, PP2B and PP5 to the regulation of tau phosphorylation. Eur J Neurosci 22, 1942-1950.

Liu, M. C., Kobeissy, F., Zheng, W. et al. (2011) Dual vulnerability of tau to calpains and caspase-3 proteolysis under neurotoxic and neurodegenerative conditions. ASN Neuro 3, e00051.

Liu, T.-C. and Kirn, D. H. (2007) Problems, Side Effects, and Disappointments in Clinical Cancer Gene Therapy. In: Gene Therapy for Cancer, (K. K. Hunt, S. A. Vorburger and S. G. Swisher eds.), pp. 351-385. Humana Press, Totowa, NJ.

Liu, X.-F., Hao, J.-L., Xie, T. et al. (2017) Nrf2 as a target for prevention of age-related and diabetic cataracts by against oxidative stress. Aging Cell 16, 934-942.

Liu, Y., Walter, S., Stagi, M. et al. (2005b) LPS receptor (CD14): a receptor for phagocytosis of Alzheimer's amyloid peptide. Brain 128, 1778-1789.

Lloret, A., Badia, M.-C., Giraldo, E. et al. (2011) Amyloid- $\beta$ toxicity and tau hyperphosphorylation are linked via RCAN1 in Alzheimer's disease. J Alzheimers Dis 27, 701-709.

Ma, D.-L., Chen, F.-Q., Xu, W.-J. et al. (2015) Early intervention with glucagon-like peptide 1 analog liraglutide prevents tau hyperphosphorylation in diabetic $\mathrm{db} / \mathrm{db}$ mice. Journal of Neurochemistry 135, 301-308.

Mackenzie, I. R., Baker, M., Pickering-Brown, S. et al. (2006) The neuropathology of frontotemporal lobar degeneration caused by mutations in the progranulin gene. Brain 129, 3081-3090.

Makar, T. K., Bever, C. T., Singh, I. S. et al. (2009) Brain-derived neurotrophic factor gene delivery in an animal model of multiple sclerosis using bone marrow stem cells as a vehicle. Journal of Neuroimmunology 210, 40-51.

Marino Gammazza, A., Bavisotto, C. C., Barone, R., de Macario, E. C. and Macario, A. J. (2016) Alzheimer's Disease and Molecular Chaperones: Current Knowledge and the Future of Chaperonotherapy. Curr Pharm Des 22, 4040-4049.

Markesbery, W. R. (1997) Oxidative Stress Hypothesis in Alzheimer's Disease. Free Radical Biology and Medicine 23, 134-147.

Marr, R. A., Rockenstein, E., Mukherjee, A. et al. (2003) Neprilysin gene transfer reduces human amyloid pathology in transgenic mice. J Neurosci 23, 1992-1996.

Mattson, M. P., Cheng, B., Culwell, A. R. et al. (1993) Evidence for excitoprotective and intraneuronal calcium-regulating roles for secreted forms of the beta-amyloid precursor protein. Neuron 10, 243-254.

Mattsson-Carlgren, N., Janelidze, S., Palmqvist, S., et al. (2020) Longitudinal plasma p-tau217 is increased in early stages of Alzheimer's disease. Brain . DOI: 10.1093/brain/awaa286. Online ahead of print.

Mawuenyega, K. G., Sigurdson, W., Ovod, V. et al. (2010) Decreased clearance of CNS beta-amyloid in Alzheimer's disease. Science (New York, N.Y.) 330, 1774-1774. 
Mayford, M., Baranes, D., Podsypanina, K. and Kandel, E. R. (1996) The 3'-untranslated region of CaMKII alpha is a cis-acting signal for the localization and translation of mRNA in dendrites. Proc Natl Acad Sci U S A 93, 13250-13255.

McClean, P. L., Parthsarathy, V., Faivre, E. and Hölscher, C. (2011) The Diabetes Drug Liraglutide Prevents Degenerative Processes in a Mouse Model of Alzheimer\&\#039;s Disease. The Journal of Neuroscience 31, 6587.

Mehta, D., Jackson, R., Paul, G., Shi, J. and Sabbagh, M. (2017) Why do trials for Alzheimer's disease drugs keep failing? A discontinued drug perspective for 2010-2015. Expert Opin Investig Drugs 26, 735-739.

Mehta, M., Adem, A. and Sabbagh, M. (2012) New acetylcholinesterase inhibitors for Alzheimer's disease. Int J Alzheimers Dis 2012, 728983.

Michalon, A., Koshibu, K., Baumgärtel, K., Spirig, D. H. and Mansuy, I. M. (2005) Inducible and neuron-specific gene expression in the adult mouse brain with the rtTA2S-M2 system. genesis 43, 205-212.

Mirończuk-Chodakowska, I., Witkowska, A. M. and Zujko, M. E. (2018) Endogenous non-enzymatic antioxidants in the human body. Advances in Medical Sciences 63, 68-78.

Mori, H., Takio, K., Ogawara, M. and Selkoe, D. J. (1992) Mass spectrometry of purified amyloid beta protein in Alzheimer's disease. J Biol Chem 267, 17082-17086.

Moss, L. et al. (2011) ADAM9 inhibition increases membrane activity of ADAM10 and controls $\alpha$ secretase processing of the amyloid precursor protein. Journal of Biological Chemistry 286, 40443-40451.

Moussa-Pacha, N., Abdin, S., Omar, H., Alniss, H. and Al-Tel, T. (2020) BACE1 inhibitors: Current status and future directions in treating Alzheimer's disease. Med Res Rev 40, 339-384.

Mussmann, R., Geese, M., Harder, F. et al. (2007) Inhibition of GSK3 promotes replication and survival of pancreatic beta cells. J Biol Chem 282, 12030-12037.

Nagahara, A. H., Mateling, M., Kovacs, I. et al. (2013) Early BDNF treatment ameliorates cell loss in the entorhinal cortex of APP transgenic mice. J Neurosci 33, 15596-15602.

Nagahara, A. H., Merrill, D. A., Coppola, G. et al. (2009) Neuroprotective effects of brain-derived neurotrophic factor in rodent and primate models of Alzheimer's disease. Nature Medicine 15, 331-337.

Nagahara, A. H., Wilson, B. R., Ivasyk, I. et al. (2018) MR-guided delivery of AAV2-BDNF into the entorhinal cortex of non-human primates. Gene Therapy 25, 104-114.

Naidoo, J. and Young, D. (2012) Gene regulation systems for gene therapy applications in the central nervous system. Neurol Res Int 2012, 595410.

Narisawa-Saito, M., Wakabayashi, K., Tsuji, S., Takahashi, H. and Nawa, H. (1996) Regional specificity of alterations in NGF, BDNF and NT-3 levels in Alzheimer's disease. NeuroReport 7.

Nieznanski, K., Choi, J. K., Chen, S., Surewicz, K. and Surewicz, W. K. (2012) Soluble prion protein inhibits amyloid- $\beta$ (A $\beta$ ) fibrillization and toxicity. J Biol Chem 287, 33104-33108.

Nikol, S. and Huehns, T. Y. (2001) Preclinical and clinical experience in vascular gene therapy: advantages over conservative/standard therapy. J Invasive Cardiol 13, 333-338.

Nilson, A. N., English, K. C., Gerson, J. E. et al. (2017) Tau Oligomers Associate with Inflammation in the Brain and Retina of Tauopathy Mice and in Neurodegenerative Diseases. J Alzheimers Dis 55, 1083-1099.

Nimmrich, V., Grimm, C., Draguhn, A. et al. (2008) Amyloid beta oligomers (A beta(1-42) globulomer) suppress spontaneous synaptic activity by inhibition of P/Q-type calcium currents. J Neurosci 28, 788-797.

Nixon, R., Cataldo, A. and Matthews, P. (2000) The endosomal-lysosomal system of neurons in Alzheimer's disease pathogenesis: a review. Neurochem. Res. 25, 1161-1172.

Nixon, R. A., Wegiel, J., Kumar, A. et al. (2005) Extensive Involvement of Autophagy in Alzheimer Disease: An Immuno-Electron Microscopy Study. Journal of Neuropathology \& Experimental Neurology 64, 113-122. 
Nixon, R. and Cataldo, A. (2006) Lysosomal system pathways: genes to neurodegeneration in Alzheimer's disease. J. Alzheimer's Dis. 9, 277-289.

Nunan, J. and Small, D. H. (2000) Regulation of APP cleavage by $\alpha-, \beta$ - and $\gamma$-secretases. FEBS Letters 483, 6-10.

Obregon, D., Hou, H., Deng, J. et al. (2012) Soluble amyloid precursor protein- $\alpha$ modulates $\beta$ secretase activity and amyloid- $\beta$ generation. Nat Commun 3, 777-777.

Palmqvist, S., Janelidze, S., Quiroz, Y. et al. (2020) Discriminative accuracy of plasma phospho-tau217 for Alzheimer's disease vs other neurodegenerative disorders. JAMA 324, 772-781.

Parkin, E. and Harris, B. (2009) A disintegrin and metallaproteinase (ADAM)-mediated ectodomain shedding of ADAM10. Journal of Neurochemistry 108, 1464-1479.

Peel, A. L., Zolotukhin, S., Schrimsher, G. W., Muzyczka, N. and Reier, P. J. (1997) Efficient transduction of green fluorescent protein in spinal cord neurons using adeno-associated virus vectors containing cell type-specific promoters. Gene Ther 4, 16-24.

Perl, D. P. (2010) Neuropathology of Alzheimer's disease. Mt Sinai J Med 77, 32-42.

Peron, R., Vatanabe, I. P., Manzine, P. R., Camins, A. and Cominetti, M. R. (2018) Alpha-Secretase ADAM10 Regulation: Insights into Alzheimer's Disease Treatment. Pharmaceuticals (Basel) $11,12$.

Perry, D. C., Lehmann, M., Yokoyama, J. S. et al. (2013) Progranulin mutations as risk factors for Alzheimer disease. JAMA Neurol 70, 774-778.

Perry, T., Lahiri, D. K., Sambamurti, K. et al. (2003) Glucagon-like peptide-1 decreases endogenous amyloid- $\beta$ peptide $(A \beta)$ levels and protects hippocampal neurons from death induced by $A \beta$ and iron. Journal of Neuroscience Research 72, 603-612.

Perry, T. A. and Greig, N. H. (2004) A new Alzheimer's disease interventive strategy: GLP-1. Curr Drug Targets 5, 565-571.

Planel, E., Yasutake, K., Fujita, S. C. and Ishiguro, K. (2001) Inhibition of protein phosphatase 2A overrides tau protein kinase I/glycogen synthase kinase 3 beta and cyclin-dependent kinase 5 inhibition and results in tau hyperphosphorylation in the hippocampus of starved mouse. $J$ Biol Chem 276, 34298-34306.

Pohlkamp, T., Steller, L., May, P. et al. (2014) Generation and characterization of an Nse-CreERT2 transgenic line suitable for inducible gene manipulation in cerebellar granule cells. PloS one 9, e100384-e100384.

Postina, R., Schroeder, A., Dewachter, I. et al. (2004) A disintegrin-metalloproteinase prevents amyloid plaque formation and hippocampal defects in an Alzheimer disease mouse model. J Clin Invest 113, 1456-1464.

Prevail Therapeutics (2020) Prevail Therapeutics Announces Investigational New Drug Application Active for PR006 for the Treatment of Frontotemporal Dementia with GRN Mutation.

Priller, C., Bauer, T., Mitteregger, G. et al. (2006) Synapse Formation and Function Is Modulated by the Amyloid Precursor Protein. The Journal of Neuroscience 26, 7212.

Prince, M., Wimo, A., Guerchet, M. et al. (2015) World Alzheimer Report 2015, The Global Impact of Dementia: An analysis of prevalence, incidence, cost and trends.

Rafii, M. S., Baumann, T. L., Bakay, R. A. E. et al. (2014) A phase1 study of stereotactic gene delivery of AAV2-NGF for Alzheimer's disease. Alzheimer's \& Dementia 10, 571-581.

Rafii, M. S., Tuszynski, M. H., Thomas, R. G. et al. (2018) Adeno-Associated Viral Vector (Serotype 2)Nerve Growth Factor for Patients With Alzheimer Disease: A Randomized Clinical Trial. JAMA Neurol 75, 834-841.

Rall, S. C., Jr., Weisgraber, K. H. and Mahley, R. W. (1982) Human apolipoprotein E. The complete amino acid sequence. J Biol Chem 257, 4171-4178.

Rogers, J., Luber-Narod, J., Styren, S. D. and Civin, W. H. (1988) Expression of immune systemassociated antigens by cells of the human central nervous system: relationship to the pathology of Alzheimer's disease. Neurobiol Aging 9, 339-349. 
Rosenberg, J. B., Kaplitt, M. G., De, B. P. et al. (2018) AAVrh.10-Mediated APOE2 Central Nervous System Gene Therapy for APOE4-Associated Alzheimer's Disease. Hum Gene Ther Clin Dev 29, 24-47.

Saido, T. and Leissring, M. A. (2012) Proteolytic degradation of amyloid $\beta$-protein. Cold Spring Harb Perspect Med 2, a006379-a006379.

Salazar, S. V. and Strittmatter, S. M. (2017) Cellular prion protein as a receptor for amyloid- $\beta$ oligomers in Alzheimer's disease. Biochemical and biophysical research communications 483, 1143-1147.

Sano, M., Ernesto, C., Thomas, R. G. et al. (1997) A controlled trial of selegiline, alpha-tocopherol, or both as treatment for Alzheimer's disease. The Alzheimer's Disease Cooperative Study. N Engl J Med 336, 1216-1222.

Scharfenberg, F., Helbig, A., Sammel, M. et al. (2019) Degradome of soluble ADAM10 and ADAM17 metalloproteases. Cellular and Molecular Life Sciences 77, 331-350.

Schmid, C. D., Sautkulis, L. N., Danielson, P. E. et al. (2002) Heterogeneous expression of the triggering receptor expressed on myeloid cells- 2 on adult murine microglia. Journal of neurochemistry $83,1309-1320$.

Schmitt, H. P. (2005) On the paradox of ion channel blockade and its benefits in the treatment of Alzheimer disease. Med Hypotheses 65, 259-265.

Schwartzentruber, D. J., Kirkwood, J. M., Guarino, M. J. et al. (2011) Immunotherapy of advanced melanoma by intratumoral injections of autologous, purified dendritic cells transduced with gene construct of interleukin-12, with dose-dependent expression under the control of an oral activator ligand. Journal of Clinical Oncology 29, 2540-2540.

Selkoe, D. J. (1991) The molecular pathology of Alzheimer's disease. Neuron 6, 487-498.

Selkoe, D. (2019) $\beta$-secretase inhibitors for the treatment of Alzheimer's Disease: Heading in the wrong direction? Lancet Neurol. 18, 624-626.

Sengupta, S., Horowitz, P. M., Karsten, S. L. et al. (2006) Degradation of tau protein by puromycinsensitive aminopeptidase in vitro. Biochemistry 45, 15111-15119.

Shaikh, S. and Nicholson, L. F. (2006) Optimization of the Tet-On system for inducible expression of RAGE. J Biomol Tech 17, 283-292.

Sharma, M. K., Jalewa, J. and Hölscher, C. (2014) Neuroprotective and anti-apoptotic effects of liraglutide on SH-SY5Y cells exposed to methylglyoxal stress. J Neurochem 128, 459-471.

Shinall, H., Song, E. S. and Hersh, L. B. (2005) Susceptibility of amyloid beta peptide degrading enzymes to oxidative damage: a potential Alzheimer's disease spiral. Biochemistry 44, 15345-15350.

Shinohara, M., Tachibana, M., Kanekiyo, T. and Bu, G. (2017) Role of LRP1 in the pathogenesis of Alzheimer's disease: evidence from clinical and preclinical studies. J Lipid Res 58, 1267-1281.

Shirley, J., de Jong, Y., Terorst, C. and Herzog, R. (2020) Immune responses to viral gene therapy vectors. Molecular Therapy 28, 709-722.

Somia, N. and Verma, I. M. (2000) Gene therapy: trials and tribulations. Nature Reviews Genetics 1, 91-99.

Son, S. J., Lee, K. S., Chung, J. H. et al. (2015) Increased Plasma Levels of Heat Shock Protein 70 Associated with Subsequent Clinical Conversion to Mild Cognitive Impairment in Cognitively Healthy Elderly. PLOS ONE 10, e0119180.

Sontag, J.-M. and Sontag, E. (2014) Protein phosphatase 2A dysfunction in Alzheimer's disease. Front Mol Neurosci 7, 16-16.

Spencer, B., Marr, R. A., Rockenstein, E. et al. (2008) Long-term neprilysin gene transfer is associated with reduced levels of intracellular Abeta and behavioral improvement in APP transgenic mice. BMC Neurosci 9, 109.

Spielman, L. and Klegeris, A. (2014) The Role of Insulin and Incretins in Neuroinflammation and Neurodegeneration. Immunoendocrinology 1. 
Stalder, M., Phinney, A., Probst, A. et al. (1999) Association of microglia with amyloid plaques in brains of APP23 transgenic mice. The American journal of pathology 154, 1673-1684.

Stewart, C. R., Stuart, L. M., Wilkinson, K. et al. (2010) CD36 ligands promote sterile inflammation through assembly of a Toll-like receptor 4 and 6 heterodimer. Nat Immunol 11, 155-161.

Takahashi , K., Rochford , C. D. P. and Neumann , H. (2005) Clearance of apoptotic neurons without inflammation by microglial triggering receptor expressed on myeloid cells-2. Journal of Experimental Medicine 201, 647-657.

Takaki, Y., Iwata, N., Tsubuki, S. et al. (2000) Biochemical Identification of the Neutral Endopeptidase Family Member Responsible for the Catabolism of Amyloid $\beta$ Peptide in the Brain1. The Journal of Biochemistry 128, 897-902.

Tang, X. H. and Gudas, L. J. (2011) Retinoids, retinoic acid receptors, and cancer. Annu Rev Pathol 6, 345-364.

Tasyurek, M. H., Altunbas, H. A., Canatan, H., Griffith, T. S. and Sanlioglu, S. (2014) GLP-1-mediated gene therapy approaches for diabetes treatment. Expert Reviews in Molecular Medicine 16, e7.

Taylor, D. R., Parkin, E. T., Cocklin, S. L. et al. (2009) Role of ADAMs in the ectodomain shedding and conformational conversion of the prion protein. J Biol Chem 284, 22590-22600.

Teramoto, S., Miyamoto, N., Yatomi, K. et al. (2011) Exendin-4, a glucagon-like peptide-1 receptor agonist, provides neuroprotection in mice transient focal cerebral ischemia. J Cereb Blood Flow Metab 31, 1696-1705.

Terwel, D., Muyllaert, D., Dewachter, I. et al. (2008) Amyloid activates GSK-3beta to aggravate neuronal tauopathy in bigenic mice. Am J Pathol 172, 786-798.

Thal, D. R., Rüb, U., Orantes, M. and Braak, H. (2002) Phases of A beta-deposition in the human brain and its relevance for the development of AD. Neurology 58, 1791-1800.

Tian, Y., Wang, W., Xu, L. et al. (2019) Activation of Nrf2/ARE pathway alleviates the cognitive deficits in PS1V97L-Tg mouse model of Alzheimer's disease through modulation of oxidative stress. Journal of Neuroscience Research 97, 492-505.

Tramutola, A., Lanzillotta, C., Perluigi, M. and Butterfield, D. A. (2017) Oxidative stress, protein modification and Alzheimer disease. Brain Research Bulletin 133, 88-96.

Tsujio, I., Zaidi, T., Xu, J. et al. (2005) Inhibitors of protein phosphatase-2A from human brain structures, immunocytological localization and activities towards dephosphorylation of the Alzheimer type hyperphosphorylated tau. FEBS Letters 579, 363-372.

Tuszynski, M. H. (2007) Nerve growth factor gene delivery: Animal models to clinical trials. Developmental Neurobiology 67, 1204-1215.

Tuszynski, M. H., Thal, L., Pay, M. et al. (2005) A phase 1 clinical trial of nerve growth factor gene therapy for Alzheimer disease. Nature Medicine 11, 551-555.

Tuszynski, M. H., Yang, J. H., Barba, D. et al. (2015) Nerve Growth Factor Gene Therapy: Activation of Neuronal Responses in Alzheimer Disease. JAMA Neurol 72, 1139-1147.

Van Damme, P., Van Hoecke, A., Lambrechts, D. et al. (2008) Progranulin functions as a neurotrophic factor to regulate neurite outgrowth and enhance neuronal survival. J Cell Biol 181, 37-41.

van Marum, R. J. (2009) Update on the use of memantine in Alzheimer's disease. Neuropsychiatr Dis Treat 5, 237-247.

Vassar, R., Bennett, B. D., Babu-Khan, S. et al. (1999) $\beta$-Secretase Cleavage of Alzheimer's Amyloid Precursor Protein by the Transmembrane Aspartic Protease BACE. Science 286, 735-741.

Verma, M., Vats, A. and Taneja, V. (2015) Toxic species in amyloid disorders: Oligomers or mature fibrils. Ann Indian Acad Neurol 18, 138-145.

Vincent, B., Paitel, E., Saftig, P. et al. (2001) The disintegrins ADAM10 and TACE contribute to the constitutive and phorbol ester-regulated normal cleavage of the cellular prion protein. J Biol Chem 276, 37743-37746.

Virshup, D. M. and Shenolikar, S. (2009) From Promiscuity to Precision: Protein Phosphatases Get a Makeover. Molecular Cell 33, 537-545. 
Vives-Bauza, C., Zhou, C., Huang, Y. et al. (2010) PINK1-dependent recruitment of Parkin to mitochondria in mitophagy. Proc Natl Acad Sci U S A 107, 378-383.

Vogelsberg-Ragaglia, V., Schuck, T., Trojanowski, J. Q. and Lee, V. M. (2001) PP2A mRNA expression is quantitatively decreased in Alzheimer's disease hippocampus. Exp Neurol 168, 402-412.

Wadhwani, A., Affaneh, A., Van Gulden, S. and Kessler, J. (2019) Neuronal apolipoprotein E4 increases cell death and phosphorylated tau release in Alzheimer's Disease. Ann Neurol 85, 726-739.

Wang, C., Najm, R., Xu, Q. et al. (2018) Gain of toxic apolipoprotein E4 effects in human iPSC-derived neurons is ameliorated by a small-molecule structure corrector. Nature Medicine 24, 647657.

Wang, D.-S., Iwata, N., Hama, E., Saido, T. C. and Dickson, D. W. (2003) Oxidized neprilysin in aging and Alzheimer's disease brains. Biochemical and Biophysical Research Communications 310, 236-241.

Wang, Y. and Mandelkow, E. (2012) Degradation of tau protein by autophagy and proteasomal pathways. Biochemical Society Transactions 40, 644-652.

Wang, Y. P., Biernat, J., Pickhardt, M., Mandelkow, E. and Mandelkow, E. M. (2007) Stepwise proteolysis liberates tau fragments that nucleate the Alzheimer-like aggregation of fulllength tau in a neuronal cell model. Proc Natl Acad Sci U S A 104, 10252-10257.

Wei, Q., Holzer, M., Brueckner, M. K., Liu, Y. and Arendt, T. (2002) Dephosphorylation of Tau Protein by Calcineurin Triturated into Neural Living Cells. Cellular and Molecular Neurobiology 22, 13-24.

Weingarten, M. D., Lockwood, A. H., Hwo, S. Y. and Kirschner, M. W. (1975) A protein factor essential for microtubule assembly. Proc Natl Acad Sci U S A 72, 1858-1862.

Wessels, A., Lines, C., Stern, R. et al. (2020) Cognitive outcomes in trials of two BACE inhibitors in Alzheimer's disease. Alzheimers Dement. 16, 1483-1492.

Wetzel, S., Seipold, L. and Saftig, P. (2017) The metalloproteinase ADAM10: A useful therapeutic target? Biochimica et Biophysica Acta (BBA) - Molecular Cell Research 1864, 2071-2081.

Whitehouse, P. J., Price, D. L., Clark, A. W., Coyle, J. T. and DeLong, M. R. (1981) Alzheimer disease: evidence for selective loss of cholinergic neurons in the nucleus basalis. Ann Neurol 10, 122126.

Whitehouse, P. J., Price, D. L., Struble, R. G. et al. (1982) Alzheimer's disease and senile dementia: loss of neurons in the basal forebrain. Science 215, 1237-1239.

Wilhelmus, M. M. M., de Waal, R. M. W. and Verbeek, M. M. (2007) Heat shock proteins and amateur chaperones in amyloid-Beta accumulation and clearance in Alzheimer's disease. Mol Neurobiol 35, 203-216.

Yamada, K., Patel, T. K., Hochgräfe, K. et al. (2015) Analysis of in vivo turnover of tau in a mouse model of tauopathy. Mol Neurodegener 10, 55.

Yildirim Simsir, I., Soyaltin, U. E. and Cetinkalp, S. (2018) Glucagon like peptide-1 (GLP-1) likes Alzheimer's disease. Diabetes \& Metabolic Syndrome: Clinical Research \& Reviews 12, 469475.

Yin, F., Banerjee, R., Thomas, B. et al. (2010) Exaggerated inflammation, impaired host defense, and neuropathology in progranulin-deficient mice. J Exp Med 207, 117-128.

Yu, C.-E., Bird, T. D., Bekris, L. M. et al. (2010) The spectrum of mutations in progranulin: a collaborative study screening 545 cases of neurodegeneration. Archives of neurology 67, 161-170.

Yuan, S., Lei, S. and Wu, S. (2013) ADAM10 is overexpressed in human hepatocellular carcinoma and contributes to the proliferation, invasion and migration of HepG2 cells. Oncol Rep 30, 17151722.

Zhang, Y., Ma, R.-H., Li, X.-C. et al. (2014) Silencing I2PP2A Rescues Tau Pathologies and Memory Deficits through Rescuing PP2A and Inhibiting GSK-3 $\beta$ Signaling in Human Tau Transgenic Mice. Front Aging Neurosci 6. 
Zhang, W., Bai, S., Yang, J. et al. (2020) FoxO1 overexpression reduces $A \beta$ production and tau phosphorylation in vitro. Neuroscience Letters $738,135322$.

Zhao, L., Gottesdiener, A. J., Parmar, M. et al. (2016) Intracerebral adeno-associated virus gene delivery of apolipoprotein E2 markedly reduces brain amyloid pathology in Alzheimer's disease mouse models. Neurobiology of Aging 44, 159-172.

Zhao, J., Liu, X., Xia, W., Zhang, Y. and Wang, C. (2020) Frontiers in Molecular Neuroscience 13, 137.

Zheng, W. H., Bastianetto, S., Mennicken, F., Ma, W. and Kar, S. (2002) Amyloid $\beta$ peptide induces tau phosphorylation and loss of cholinergic neurons in rat primary septal cultures. Neuroscience 115, 201-211.

Zhou, L., McInnes, J., Wierda, K. et al. (2017) Tau association with synaptic vesicles causes presynaptic dysfunction. Nat Commun 8, 15295-15295.

Zhou, X., Vink, M., Klaver, B., Berkhout, B. and Das, A. T. (2006) Optimization of the Tet-On system for regulated gene expression through viral evolution. Gene Ther 13, 1382-1390.

Zhu, X., Rottkamp, C. A., Boux, H. et al. (2000) Activation of p38 Kinase Links Tau Phosphorylation, Oxidative Stress, and Cell Cycle-Related Events in Alzheimer Disease. Journal of Neuropathology \& Experimental Neurology 59, 880-888. 
Figure 1: Inter-relationships between pathogenic events culminating in neuronal injury and disease exacerbation in AD. APP can be cleaved by ADAM10, forming neuroprotective SAPP $\alpha$ and, following $\gamma$-secretase cleavage, P3 and AICD. Alternatively, BACE1 cleavage results in A $\beta$ peptide formation, which can misfold and accumulate into oligomers and fibrils, leading to oxidative stress, neuroinflammation and tau hyperphosphorylation. Tau hyperphosphorylation can occur independently of $A \beta$-peptide accumulation, resulting in its dissociation from microtubules and accumulation in PHFs and NFTs. Pink boxes denote the detrimental effects of these pathways whilst green boxes denote mechanisms leading to reduced $A \beta$-peptide or tau accumulation. Yellow bolts denote putative therapeutic targets for gene therapy-mediated overexpression. 
Table 1: Summary of potential gene therapies for AD discussed in this review.

1

3

4

5

6

7

8

9

10

11

12

13

14

15
Outcomes

Preclinical AAV

GC-1 $\alpha$ Preclinical Lentivirus

Preclinical Lentivirus

Lentivirus

AAV

Lentivirus

HSV

Preclinical AAV

Preclinical Lentivirus

AAV

AAV

AAV

Phase I

AAV

Preclinical Lentivirus

Preclinical AAV

Preclinical Lentivirus

Preclinical AAV

Preclinical AAV

Preclinical Various

Phase I

Fibroblasts

AAV

Fibroblasts

and AAV

Phase II AAV

Preclinical Lentivirus

SeV

Lentivirus

AAV

BDNF Preclinical Lentivirus

(via CBP)

GRN Preclinical AAV

GLP-1 Preclinical Various

TREM2 Preclinical Lentivirus

Nrf2 Preclinical Lentivirus
Reduced A $\beta$-peptide accumulation and improved synaptic plasticity, spine density and spatial memory in PS1 $\triangle \mathrm{E} 9$ mice.

Reduced BACE1 and $A \beta$ plaques, improved spatial memory, and attenuation of neuroinflammation in APP23 mice.

Reduced A $\beta$-peptide deposits in two transgenic human APP mouse models.

Reduced Aß-peptide, IL-6 levels, and oxidative stress in APPswe/PS1 $\triangle$ E9 mice.

Reduced A $\beta$-peptide accumulation and improved memory in APP23 mice.

Reduced intracellular $A \beta$-peptide and improved spatial memory in J9M mice.

Reduced $\mathrm{A} \beta$-peptide production in $\mathrm{C} 57 \mathrm{BL} / 6$ mice transfected with lentiviral APPswe.

Reduction in total A $\beta$-peptide load and fibrillar A $\beta$ in APP+PS1 mice.

Reduction in total A $\beta$-peptide burden in PDAPP mice.

Reduced soluble A $\beta$-peptide and synapse loss in APPswe/PS1 $\triangle E 9$ mice.

Reduction in ApoE4-dependent amyloid pathology in several transgenic mice models.

Intracisternal administration optimal method in non-human primates.

Ongoing in 15 ApoeE4 homozygotes.

Inhibition of GSK-3 $\beta$ and tau hyperphosphorylation, improved memory and spine density in human tau mice.

Protected neurons from toxicity of $\alpha$-synuclein in a PD mouse model. Could be used to induce autophagy in AD.

Increased levels of autophagic markers, and a reduction in A $\beta$-peptide levels and oxidative stress in 3xTg-AD mice.

Attenuation of neuroinflammation and reduced A $\beta$-peptide load in APP+PS1 mice.

No effect on A $\beta$-peptide deposition but reduced neuroinflammation in APP+PS1 mice.

Prevention of cholinergic neurodegeneration and improvement in memory function in various models.

Slowed cognitive decline and showed no long-term adverse effects in 8 mild AD patients.

Long-term NGF expression was well-tolerated in $10 \mathrm{AD}$ patients.

References

(Fol et al. 2016)

(Katsouri et al. 2016)

(Marr et al. 2003)

(El-Amouri et al. 2008)

(Iwata et al. 2013)

(Spencer et al. 2008)

(Hong et al. 2006)

(Carty et al. 2008)

(Dodart et al. 2005)

(Hudry et al. 2013)

(Zhao et al. 2016)

(Rosenberg et al. 2018)

NCT03634007

(Zhang et al. 2014)

(Decressac et al. 2013)

(Khandelwal et al. 2011)

(Kiyota et al. 2010)

(Kiyota et al. 2012)

(Tuszynski 2007)

(Tuszynski et al. 2005)

(Rafii et al. 2014)

(Tuszynski et al. 2015) side of injection.

No difference in primary outcomes to those administered sham injection.

(Rafii et al. 2018)

(Nagahara et al. 2009)

(Iwasaki et al. 2012)

Improved memory and reduced synaptic degeneration in Tg2576 mice.

Prevention of neuronal loss following early administration in $\mathrm{J} 20$ mice.

(Nagahara et al. 2013)

(Nagahara et al. 2018)

(Caccamo et al. 2010)

Increased BDNF levels leading to rescued memory impairment in 3xTg-AD mice.

Reduced microgliosis and improved lysosomal function in a frontotemporal dementia mouse model.

Successful overexpression of GLP-1 leading to therapeutic effects in animal models of type 2 diabetes mellitus.

Decreased $A \beta$-peptide burden, protection against synapse loss, and improved memory in APPswe/PS1 1 E9 mice.

Reduced A $\beta$-peptide burden and improvement in learning in APP/PS1 mice.
(Arrant et al. 2018)

(Tasyurek et al. 2014)

(Jiang et al. 2014)

(Kanninen et al. 2009) 
Figure 1.

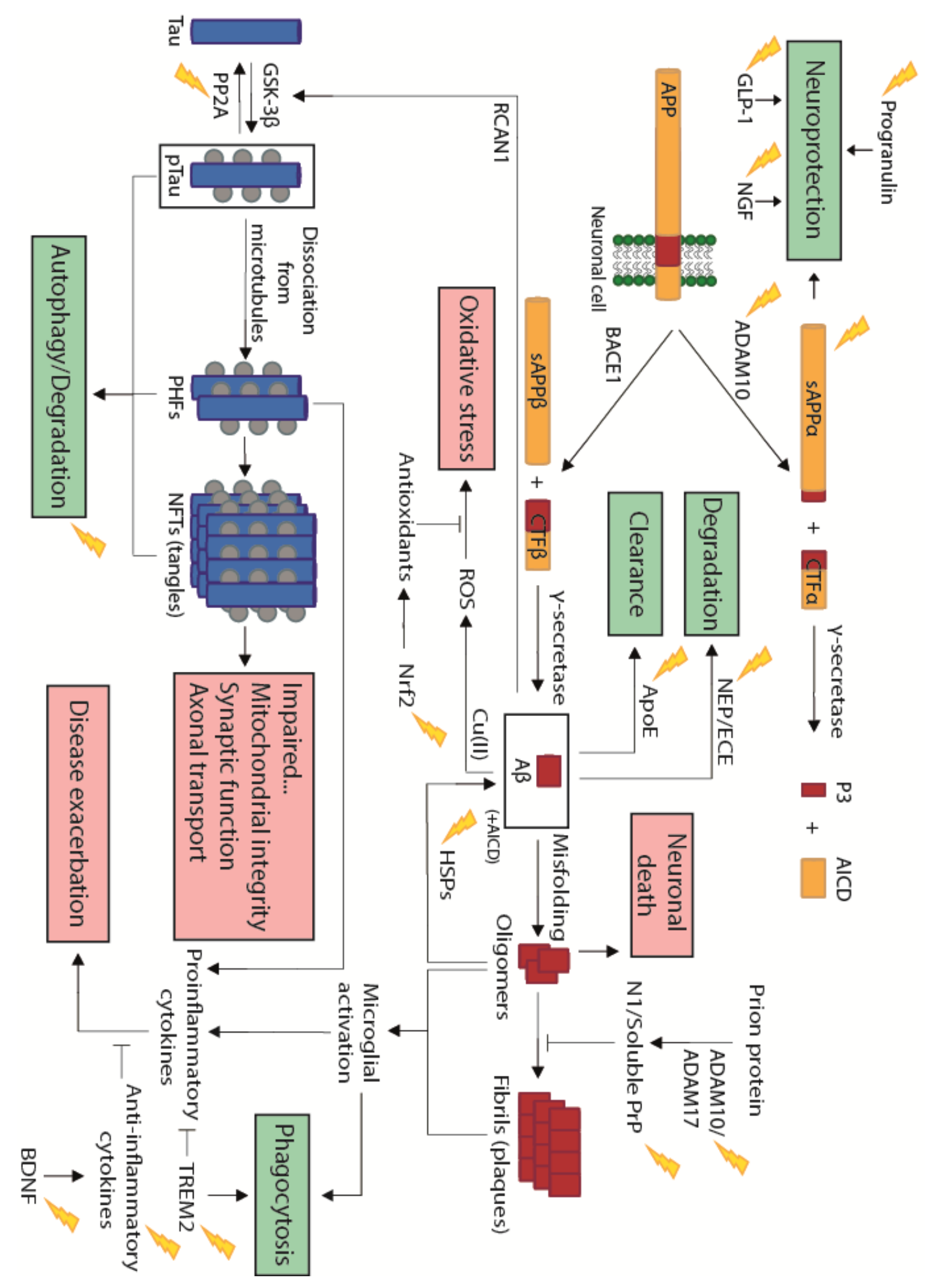

